University of Tennessee Health Science Center

UTHSC Digital Commons

\title{
Pain Management in Nursing Home Residents with Cancer and Dementia with and without Hospice Services
}

Todd Bryant Monroe

University of Tennessee Health Science Center

Follow this and additional works at: https://dc.uthsc.edu/dissertations

Part of the Health Services Research Commons, Neoplasms Commons, and the Nervous System Diseases Commons

\section{Recommended Citation}

Monroe, Todd Bryant , "Pain Management in Nursing Home Residents with Cancer and Dementia with and without Hospice Services" (2010). Theses and Dissertations (ETD). Paper 183. http://dx.doi.org/ 10.21007/etd.cghs.2010.0216.

This Dissertation is brought to you for free and open access by the College of Graduate Health Sciences at UTHSC Digital Commons. It has been accepted for inclusion in Theses and Dissertations (ETD) by an authorized administrator of UTHSC Digital Commons. For more information, please contact jwelch30@uthsc.edu. 


\title{
Pain Management in Nursing Home Residents with Cancer and Dementia with and without Hospice Services
}

\begin{abstract}
Aims: We sought to identify differences in pain management between two groups; nursing home residents with malignant cancer and dementia with and without hospice services.

Methods: Decedent records from 2003-2009 were assessed for diagnosis of dementia and cause of death as cancer. Ten malignant cancer diagnoses were determined a priori from the CDC 2004 data on the top 10 malignant cancers for all races and genders. Fifty-five decedents from 10 nursing homes were included in the final sample. Four instruments were used: Minimum Data Set (MDS) a standardized assessment tool required of most U.S. nursing homes. A large comprehensive assessment is conducted yearly followed by smaller quarterly assessments. The MDS collects demographic and diagnostic variables, as well as clinical, functional, psychosocial, and cognitive assessments. Cognitive Performance Scale (CPS scored from 1 borderline-intact to 6 very severe impairment); Discomfort Behavior Scale (DBS scored from 0 no discomfort behavior identified to 102 maximum identifiable discomfort behavior); and Equivalent Dose Units (EDU's) of opioid analgesic calculated and totaled over the last 2 weeks of life. We calculated the CPS score from the admission MDS because we believed cognitive levels were unlikely to improve over time. DBS scores were calculated from the last MDS prior to death in an effort to capture active cancer pain at the end-of-life. We realized the last MDS assessment might have been in the previous 90 days. The study received exempt status from the office of human protection.
\end{abstract}

Results: Total EDU's were significantly greater among hospice enrollees $(U 226.5, p<.05)$. There is a significantly greater likelihood of being prescribed a scheduled narcotic analgesic (OR $5.5 ; 95 \% \mathrm{Cl}$ 1.8-18.8) and a PRN narcotic analgesic (OR 3.6; 95\% Cl 1.2-11.3) when enrolled in hospice. Nursing home residents not enrolled in hospice had a significantly $(U 195.0, p<.01)$ lower CPS scores than those enrolled in hospice. Decedents with lower cognitive levels were more likely (OR 4.9; 95\% CI 1.6-15.6) to have a DBS score of zero. Forty percent of decedents with metastatic cancer and dementia received no opioid during the last 2 weeks of life.

Conclusions: We have demonstrated that pain among nursing home residents with dementia and cancer is a serious problem. Forty percent of our decedents received no opioid at the end of life. None $(n=12)$ of the subjects identified in the lowest CPS score (6) category were enrolled in hospice. One reason appears to be blunted pain related behaviors. Among the severely cognitively impaired whose pain behaviors become blunted, scheduled pain medications may be the best way to manage their pain. Pain behavioral tools are better suited for individuals with mild and moderate cognitive impairment but become less reliable in the severely cognitively impaired. New methods for assessing pain in this highly vulnerable population are needed.

Document Type

Dissertation

Degree Name

Doctor of Philosophy (PhD)

Program

Nursing

Research Advisor

Michael A. Carter, DNSc, DNP 


\section{Keywords}

Cancer, Dementia, End of Life, Nursing Home, Pain, Pain Assessment

\section{Subject Categories}

Diseases | Health Services Research | Medicine and Health Sciences | Neoplasms | Nervous System Diseases 
PAIN MANAGEMENT IN NURSING HOME RESIDENTS WITH CANCER AND DEMENTIA WITH AND WITHOUT HOSPICE SERVICES

\author{
A Dissertation \\ Presented for \\ The Graduate Studies Council \\ The University of Tennessee \\ Health Science Center \\ In Partial Fulfillment \\ Of the Requirements for the Degree \\ Doctor of Philosophy \\ From The University of Tennessee
}

By

Todd Bryant Monroe

May 2010 
Copyright (C) 2010 by Todd Bryant Monroe All rights reserved 


\section{DEDICATION}

This dissertation is dedicated to my family who has supported my educational efforts in every way. My mother and father always believed in providing what they could to advance my educational needs. My grandmother, Bernice, has been most influential in my decision to pursue research in geriatrics. She will be 94 next month and has had severe dementia for the last decade. Grandmother lives in a nursing home in rural Arkansas where she lives her days, which were once vibrant and active, as a completely obtunded patient. I have wondered about her pain on our visits; over the years her behavioral responses to family visits have diminished. I often wonder if she hurts and if she is able to communicate or express that she is in pain. It is my sincere hope that we are able, as scientists, to find ways to better understand and manage the pain experiences of individuals like my grandmother. 


\section{ACKNOWLEDGEMENTS}

I would like to express my gratitude to several individuals who made this work possible. Most notably, I thank my primary advisor, mentor, and friend, Dr. Michael Carter, for his leadership and for mentoring me during my research and writing of this dissertation. I appreciate the guidance and support I received from my dissertation committee members: Drs. Susan Jacob, Patricia Cunningham, and Margret "Peg" Hartig from The University of Tennessee Health Science Center; Dr. Michael Huffman from The University of Memphis; and Dr. Karen Feldt from Seattle University. My deepest appreciation goes to my mother, Patricia Monroe, for her love and support of me throughout my educational career and for pushing me to achieve my fullest potential. This study was supported by The University of Tennessee Health Science Center and the Alma and Hal Reagan Fellowship 


\begin{abstract}
Aims: We sought to identify differences in pain management between two groups: nursing home residents with malignant cancer and dementia with and without hospice services.

Methods: Decedent records from 2003-2009 were assessed for diagnosis of dementia and cause of death as cancer. Ten malignant cancer diagnoses were determined a priori from the CDC 2004 data on the top 10 malignant cancers for all races and genders. Fifty-five decedents from 10 nursing homes were included in the final sample. Four instruments were used: Minimum Data Set (MDS) a standardized assessment tool required of most U.S. nursing homes. A large comprehensive assessment is conducted yearly followed by smaller quarterly assessments. The MDS collects demographic and diagnostic variables, as well as clinical, functional, psychosocial, and cognitive assessments. Cognitive Performance Scale (CPS scored from 1 borderline-intact to 6 very severe impairment); Discomfort Behavior Scale (DBS scored from 0 no discomfort behavior identified to 102 maximum identifiable discomfort behavior); and Equivalent Dose Units (EDU's) of opioid analgesic calculated and totaled over the last 2 weeks of life. We calculated the CPS score from the admission MDS because we believed cognitive levels were unlikely to improve over time. DBS scores were calculated from the last MDS prior to death in an effort to capture active cancer pain at the end-of-life. We realized the last MDS assessment might have been in the previous 90 days. The study received exempt status from the office of human protection.
\end{abstract}

Results: Total EDU's were significantly greater among hospice enrollees ( $U$ 226.5, $\mathrm{p}<.05)$. There is a significantly greater likelihood of being prescribed a scheduled narcotic analgesic (OR 5.5; 95\% CI 1.8-18.8) and a PRN narcotic analgesic (OR 3.6; 95\% CI 1.2-11.3) when enrolled in hospice. Nursing home residents not enrolled in hospice had a significantly $(U 195.0, \mathrm{p}<.01)$ lower CPS scores than those enrolled in hospice. Decedents with lower cognitive levels were more likely (OR 4.9; 95\% CI 1.615.6) to have a DBS score of zero. Forty percent of decedents with metastatic cancer and dementia received no opioid during the last 2 weeks of life.

Conclusions: We have demonstrated that pain among nursing home residents with dementia and cancer is a serious problem. Forty percent of our decedents received no opioid at the end of life. None $(n=12)$ of the subjects identified in the lowest CPS score (6) category were enrolled in hospice. One reason appears to be blunted pain related behaviors. Among the severely cognitively impaired whose pain behaviors become blunted, scheduled pain medications may be the best way to manage their pain. Pain behavioral tools are better suited for individuals with mild and moderate cognitive impairment but become less reliable in the severely cognitively impaired. New methods for assessing pain in this highly vulnerable population are needed. 


\section{TABLE OF CONTENTS}

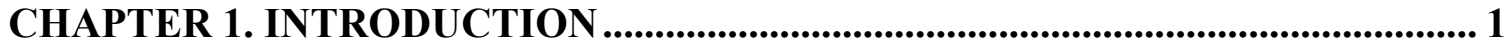

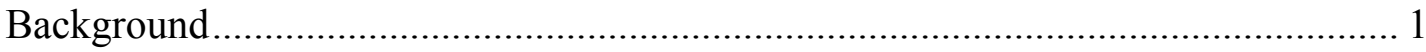

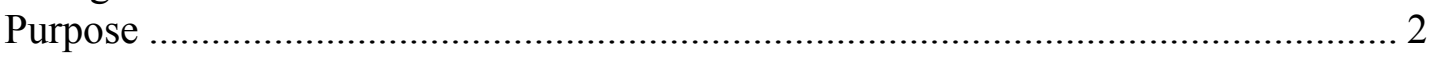

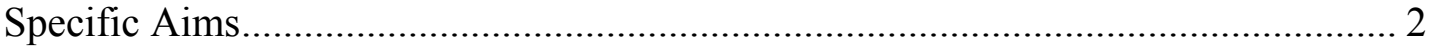

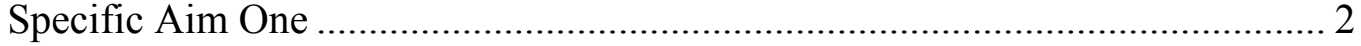

Specific Aim Two

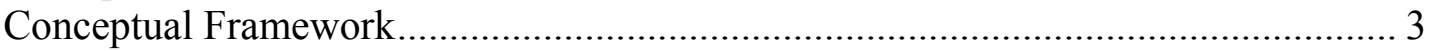

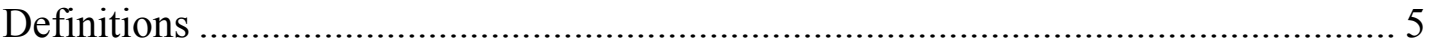

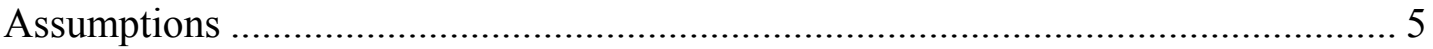

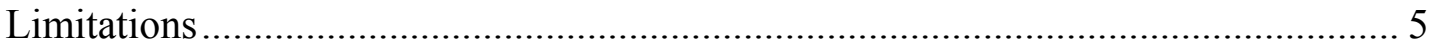

CHAPTER 2. REVIEW OF THE LITERATURE ....................................................... 7

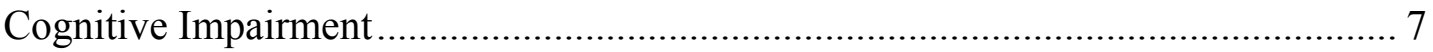

Defining Cognitive Impairment ………………………............................. 7

Measuring Cognitive Impairment..................................................................... 7

Etiology and Pathophysiology..................................................................... 7

Dementia of the Alzheimer's Type (AD) ....................................................... 7

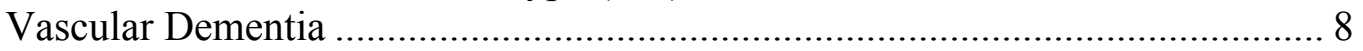

Lewey Body Dementia ................................................................................... 8

Differentiation between Dementia and Delirium ............................................... 9

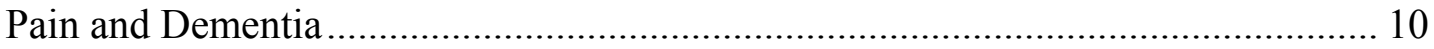

Determining the Presence of Pain in Severe Dementia.................................... 10

Current Theories Explaining Decreased Pain in Persons with Dementia .......... 11

Pain in Cognitively Impaired Nursing Home Residents............................................. 11

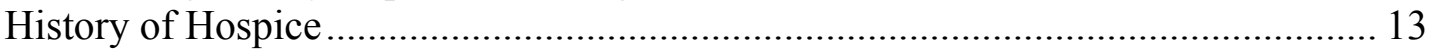

Assessing Pain in Nursing Home Residents with Cognitive Impairment ................. 13

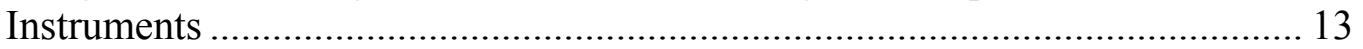

Methodological Problems Measuring Pain ....................................................... 15

Methodological Problems Measuring Cognitive Impairment ............................ 16

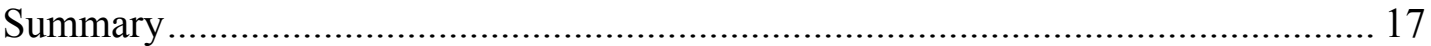

\section{CHAPTER 3. HOSPICE IN U.S. NURSING HOMES: BENEFITS AND}

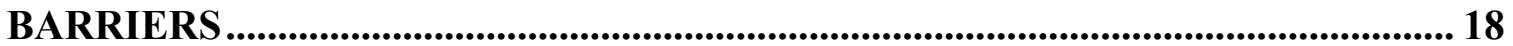

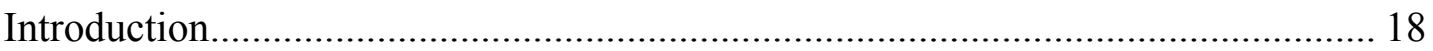

Benefits of Hospice in Nursing Homes ................................................................... 20

Better Pain and Symptom Management .......................................................... 20

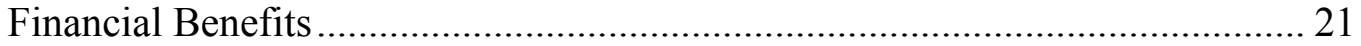

Barriers to Hospice Use .................................................................................. 22

Patient and Family Barriers ........................................................................ 22

Nursing Home Staff Barriers ......................................................................... 24

Organizational and System Issues Barriers ..................................................... 24

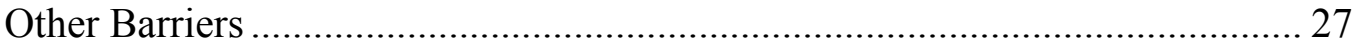

What Nurses and Other Care Providers Can Do to Increase Hospice Enrollment.... 27

Summary .................................................................................................. 29 


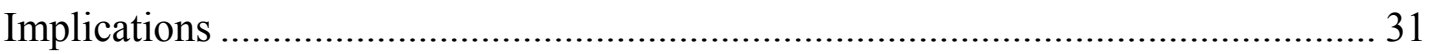

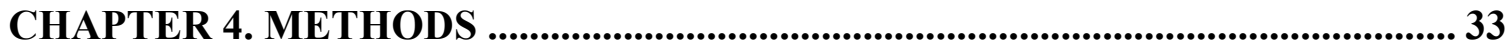

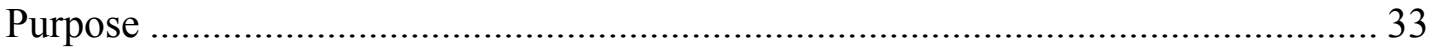

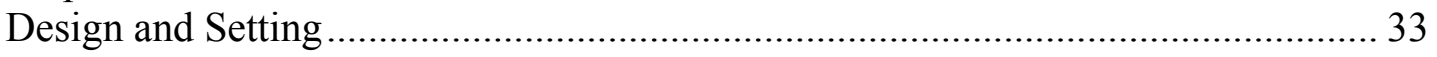

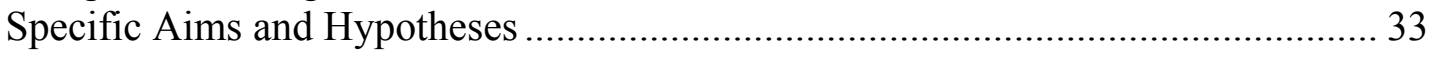

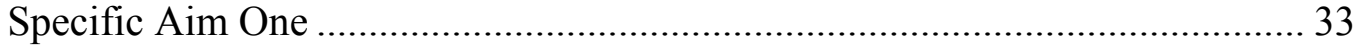

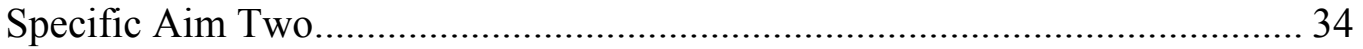

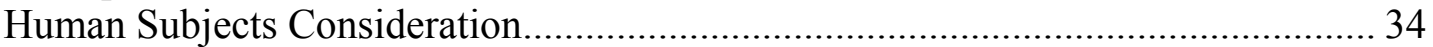

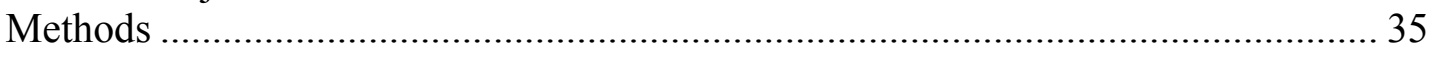

Pain Medication Administration.................................................................. 35

Demographics/Sample Characteristics ...................................................... 36

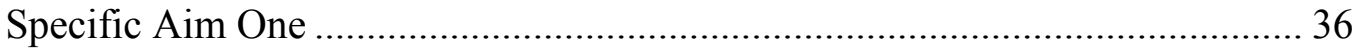

Specific Aim Two.................................................................................... 37

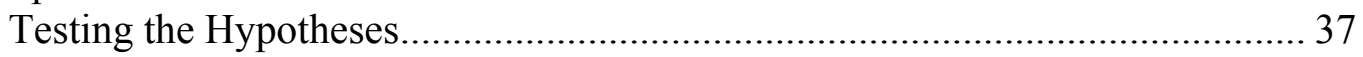

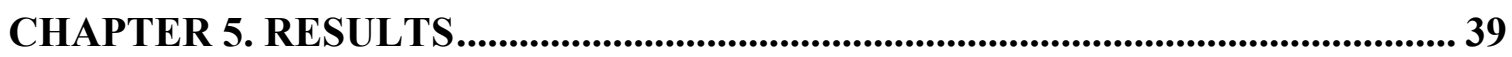

Sample Characteristics and Demographic Data .................................................. 39

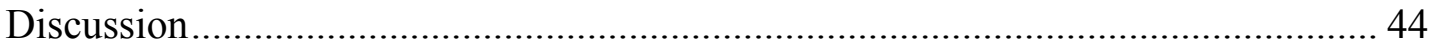

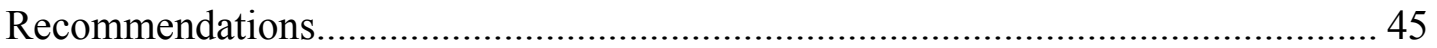

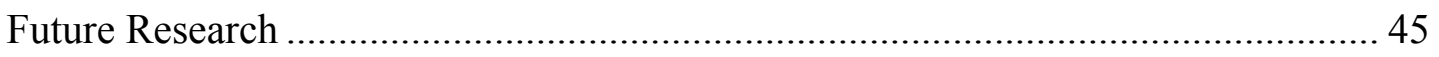

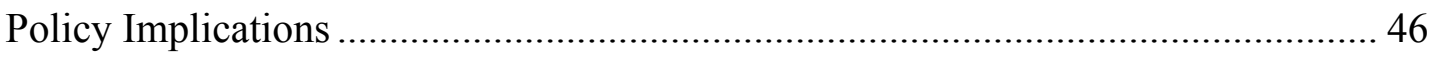

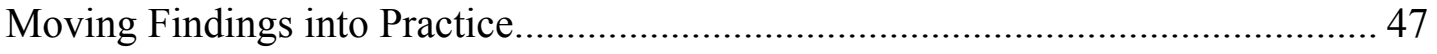

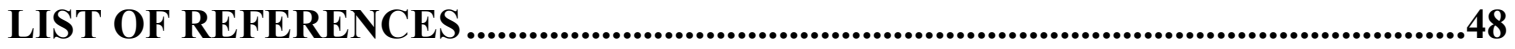

APPENDIX A. LETTER OF APPROVAL - INSTITUTIONAL REVIEW

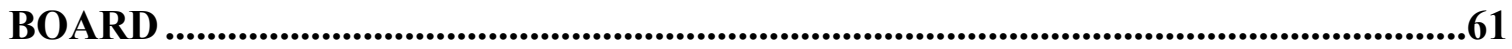

APPENDIX B. LETTER OF APPROVAL REVISION - INSTITUTIONAL

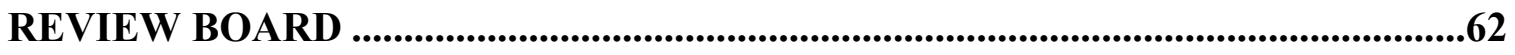

APPENDIX C. MEDICAL CHART REVIEW FORM ................................................64

VITA 


\section{LIST OF TABLES}

Table 3-1 Differences in Care between Nursing Homes and Hospice ........................... 25

Table 3-2 On-line End-of-life Educational Resources for Nurses ................................ 30

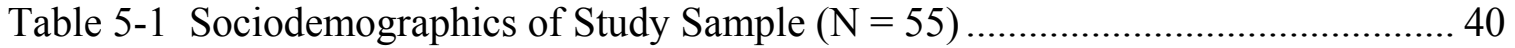

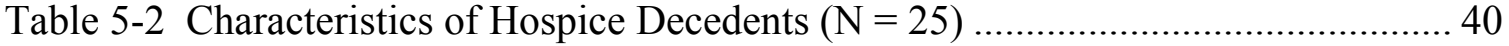

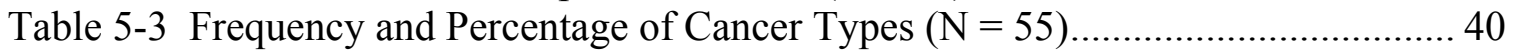

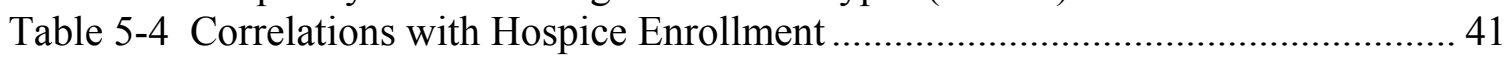

Table 5-5 Hospice Enrollment and Continuous Study Variables .................................. 41

Table 5-6 Descriptive Sample Statistic of Hospice Enrollment and Mean Rank EDU ... 41

Table 5-7 Descriptive Sample Statistics of CPS Groups .......................................... 43

Table 5-8 CPS and DBS Group Comparisons ...................................................... 43 


\section{CHAPTER 1. INTRODUCTION}

\section{BACKGROUND}

The nursing literature has long reported that nursing home residents do not consistently receive high-quality palliative care (Hanson, Sengupta, \& Slubicki, 2005), and that such environments can be deficient in end-of-life treatment (Munn, Hanson, Zimmerman, Sloane, \& Mitchell, 2006; Reynolds, Henderson, Schulman, \& Hanson, 2002). In particular, the management of pain at the end of life for nursing home residents could be much improved (Buchanan, Choi, Wang, \& Ju, 2004; Hoffman \& Tarzain, 2005); many die from conditions that cause substantial physical distress. Such residents would be well served by enrollment in hospice services, warranted when the patient has a fatal illness and requires close attention to pain management. According to one study, only a little more than a third (37.1\%) of nursing home residents with dementia who had a terminal diagnosis had daily pain or frequent pain suitable for hospice services (Mitchell, Morris, Park, \& Fries, 2004). In contrast, Munn et al. (2006) reported that residents enrolled in hospice services were $22 \%$ more likely to receive pain treatment.

Currently 20\% to 24\% (Ersek \& Wilson, 2003; Hanson, Reynolds, Henderson, \& Pickard, 2005) of all deaths in the U.S. occur in nursing homes, which means that each year approximately 480,000 to 821,000 people expire in such facilities. Researchers suggest that these percentages will double by the year 2040 (Ersek \& Wilson, 2003). The annual mortality rate in nursing homes varies from 24\% to 32\% (Dobbs, Hanson, Zimmerman, Williams, \& Munn, 2006), and first-year mortality rates hover around 34\% (Munn, et al., 2006). Investigators have found that nearly $50 \%$ of the nursing home population has dementia (Magaziner, et al., 2000). Clearly, significant numbers of older adults live and die in nursing homes. Increasing the quality of life at the end of life among nursing home residents, especially those with dementia, is a challenge.

While a patient's self-reports are the accepted standard in pain assessment, nursing home residents with cognitive impairment (CI) are frequently unable to understand and report pain, and thus such self-reports may be unreliable. This situation is complicated by the presence of depression or dementia, which can directly affect residents' perceptions.

Nurses experienced in long-term care or family members may well be able to offer assessments of a resident's pain through proxy pain ratings (McCaffery, 1999), but such accounts by individuals close to the resident often reflect their beliefs and emotional reactions to the situation. Another challenge to the accurate assessment of pain is that the typical signs associated with acute pain are not useful indicators in older adults, and currently no biological markers exist to assess pain (Davis \& Srivastava, 2003). Further, without a subjective report of pain, there can be no pain intensity rating (Pasero \& McCaffery, 2005).

The use of hospice services to assist in the appropriate and effective management of pain among nursing home residents with CI may facilitate a more dignified death. 
Hospice entails an interdisciplinary approach, addressing a patient's physical, sociologic, spiritual, and psychogenic symptoms. In one study, nursing home residents identified indicators of such a death as the maintenance of social networks, not becoming a burden to others, staying active, not being in pain, and respecting one's wishes to pass on (Pleschberger, 2007). Highly trained hospice staff offer a number of services, including pain management at the end of life (Hoffman \& Tarzain, 2005). Given a median survival time of 4 months and a mean survival time of 6.3 months for nursing home residents with severe dementia (Luchins, Hanrahan, \& Murphy, 1997), hospice services seem particularly appropriate for such patients (Cherney, 2008). Such services may offer the nursing home staff and residents' families support while simultaneously helping older adults with severe CI manage pain and ease the transition from life to death.

\section{PURPOSE}

The purpose of this study was to identify the differences in pain medication administration between two different groups of deceased subjects, nursing home residents with malignant cancer and dementia with and without hospice services.

\section{SPECIFIC AIMS}

The aims that guided this study were derived from the literature and are described next; associated hypotheses follow each study aim.

\section{Specific Aim One}

Specific Aim One was to determine the differences in administered pain medications for cognitively impaired residents who died from cancer while receiving hospice services as compared with those not receiving hospice services. The following eight hypotheses were associated with this aim.

- Hypothesis 1. Residents who received hospice services would receive more scheduled narcotic analgesic than residents who did not receive hospice services.

- Hypothesis 2. Residents who received hospice services would receive greater total equivalent dose units (EDU's) of narcotic analgesic than residents who did not receive hospice services.

- Hypothesis 3. Residents who received hospice services would receive greater total dose number of non-narcotic analgesics (TDNN) than residents who did not receive hospice services.

- Hypothesis 4. Residents who received hospice services would receive more PRN narcotic analgesic than residents who did not receive hospice services. 
- Hypothesis 5. Residents who received hospice services would receive more scheduled non-narcotic analgesic than residents who did not receive hospice services.

- Hypothesis 6. Residents who received hospice services would receive more PRN non-narcotic analgesic than residents who did not receive hospice services.

- Hypothesis 7. Residents who received hospice services would have different cognitive performance scores (CPS) than residents who did not receive hospice services.

- Hypothesis 8. Residents who received hospice services would receive greater total dose numbers of drug potentiators (TDNP) than would residents who did not receive hospice services.

\section{Specific Aim Two}

Specific Aim two was to determine if discomfort related pain behaviors among nursing home residents with cancer and dementia decrease with increasing cognitive impairment. The following hypothesis is associated with this aim.

Hypothesis 9. Discomfort related pain behaviors among all residents will be decreased with increasing cognitive impairment.

\section{CONCEPTUAL FRAMEWORK}

Hospice is an interdisciplinary healthcare practice with an emphasis on addressing the terminally ill patient's physical, sociologic, spiritual, and psychological symptoms. Hospice is warranted when a nursing home resident has an irreversible, progressive illness and is near the end of life. Hospice was founded on 10 basic principles (Connecticut Hospice, 1998) (Figure 1-1) including: the family and patient are considered the unit of care, an interdisciplinary team provides care, 24 hour availability of professional assistance, with a primary goal of pain relief and management of associated symptoms (Parham, 2002).

The hospice philosophy incorporates the biopsychosocial paradigm. Several assumptions about the origin of pain are integrated into the biopsychosocial approach (Davis \& Srivastava, 2003; Gatchel, 2004; Killinger, Morley, Kettner, \& Kauric, 2001). In this model, biological, mental health, and socio-environmental variables combine to create the pain experience and thus all require attention when treatment is planned.

This conceptual framework guided the research question that nursing home residents with malignant cancer and dementia with hospice may have different pain management than those who did not receive hospice services. 
1. The patient and family are regarded as the unit of care.

2. Services are physician directed and nurse coordinated.

3. Emphasis is on control of symptoms (physical, sociologic, spiritual, and psychogenic).

4. An interdisciplinary team provides care.

5. Trained volunteers are an integral part of the team.

6. Services are 24 hours a day, 7 days a week, on call, with emphasis on availability of medical and nursing skills.

7. Family members receive bereavement follow-up.

8. Home care and inpatient care are coordinated.

9. Patients are accepted on the basis of health needs, not on ability to pay.

10. There are structured systems for staff support and communication

Figure 1-1. 10 Principles of Hospice Care

Source: Modified with permission from Connecticut Hospice (1998). 10 principles of hospice care. Cancer Therapeutics, 1(2), 11. 


\title{
DEFINITIONS
}

The definitions that follow were used to conceptually guide and operationally define various components of this research.

- Cancer. Any one of 10 malignant ICD-9 cancer codes established a priori and a confirmatory diagnosis of cancer in the medical record. These included colorectal, female breast, prostate, lung, uterine, melanoma of the skin, ovarian, kidney, non-Hodgkin's lymphoma, and bladder.

- Dementia. For the purposes of this study dementia was defined as a diagnosis of Alzheimer's disease (Dementia of the Alzheimer's Type or DAT), Lewy body dementia, vascular dementia, or mixed as recorded in the medical record.

- Hospice. Enrollment in a Medicare approved hospice program as recorded in the medical record.

- Minimum Data Set (MDS). An assessment instrument required in all longterm care facilities that receive federal Medicare/Medicaid funds.

- Discomfort. For the purposes of this retrospective study we define discomfort behaviors as those behaviors that may indicate physical discomfort or pain. Therefore the terms "discomfort" and "pain" in this study are used interchangeably.

\begin{abstract}
ASSUMPTIONS
This study involves a retrospective analysis of patient chart information, and as such a major assumption is that these records will be accurate.

\section{LIMITATIONS}

As noted above, the author assumes that all data in the medical record were accurate; therefore, the first major limitation is that some information may not be accurate. The record may not reflect the actual care the resident the received. The nurse who administered care to the resident may not have recorded the MDS data. A diagnosis of malignant cancer does not necessarily mean the individual had active cancer upon death, however every effort to ensure active cancer was made and if undeterminable, the subject was not considered for this study. The nurse providing the care is most often an LPN and the MDS must be signed by an RN who may or may not have completed the form.
\end{abstract}

There were limitations in this retrospective study design. The convenience sample was selected over six years with multiple providers coding the MDS data and charting 
diagnoses and medication administration. The MDS has been identified with limitations when used as a research tool (Mentes, Culp, Maas, \& Rantz, 1999; Ryan, Stone, \& Raynor, 2004) and this potentially weakens the study findings. 


\section{CHAPTER 2. REVIEW OF THE LITERATURE}

\section{COGNITIVE IMPAIRMENT}

\section{Defining Cognitive Impairment}

Carr, Duchek, Meuser, and Morris (2006) define CI as a "decline in at least one of the following areas: short-term memory, attention, orientation, judgment and problemsolving-skills, and visuospatial skills." The Geriatric Research Group (n.d.) has defined CI as "short-term memory loss and difficulty finding words." Mild CI has been defined as "cognitive deficits that fall short of the diagnostic criteria for dementia" (Carr, et al., 2006, p. 1029). Additionally, mild CI has been defined as impairment without dementia or functional impairment (Plassman, et al., 2008).

\section{Measuring Cognitive Impairment}

The Cognitive Performance Scale (CPS) (Morris, et al., 1994) was developed from five MDS items and is reported both reliable and valid when an individual is trained on its use (Paquay, et al., 2007). Wu and colleagues (2003) quantified the severity of cognitive impairment with the CPS into three categories, no or mild CI (0-1), moderate CI (2-3), and severe CI (4-6). They reported that scores of 4-6 have been reported to correlate with a MMSE score of $<10$, indicating severe CI while CPS scores of 5 and 6 are equivalent to an MMSE of $<5$ (Hartmaier, et al., 1995; Morris, et al., 1994) indicating very severe impairment.

\section{Etiology and Pathophysiology}

The presence of the apoliopoprotein E-4 (APOE-4) gene and cardiovascular risk factors and hypertension have a direct association with dementia of the Alzheimer's type and vascular dementia Other genetic precursors have been identified, the APP and three other APOE alleles (APOE e1, e2, and e3) and the presenilins (Beatty, 2006). All of the APP genes lead to the production of A-beta 42, a neurotoxic amino acid sequence, which has been implicated in the formation of amyloid plaques (Beatty, 2006). It is hypothesized that amyloid plaques occur first in the pathology of dementia of the Alzheimer's type (Beatty, 2006).

\section{Dementia of the Alzheimer's Type (AD)}

The pathopysiology of Alzheimer's disease is not exactly known. Several theories are being investigated, 1) loss of neurotransmitter stimulation by choline acetyltransferase; 2) mutation for encoding amyloid precursor protein; 3) alterations in 
apoliopoprotein E, which binds beta amyloid; and 4) pathologic activation of N-methylD-asparate (NMDA) receptors resulting in an influx of excess calcium (Alzheimer's Association, 2008).

Each of these theories is linked to the formation of insoluble amyloid plaques in brain tissue and blood vessels. AD has also been linked to the breakdown of lysosomal pathways. These pathways are the precursor protein to yield beta amyloid, a neurotoxic substance coded by chromosome 21 (McCance \& Huether, 2006). Another theory is that once the plaques form, complement proteins attach to them, attracting microglia (the brains immune force), which release toxins in an attempt to destroy the plaques creating an endless cycle (Alzheimer's Association, 2008).

Additional destruction of brain tissue results when the stabilizing tau proteins detach from microtubules and form insoluble helical filaments called neurofibrillary tangles (McCance \& Huether, 2006). Further damage occurs in cerebral arteries where amyloid is deposited and groups of nerve cells degenerate around this deposited amyloid core (Alzheimer's Association, 2008). Microscopic examination reveals senile plaques, which disrupt nerve impulse transmission (Alzheimer's Association, 2008). The greater the number of senile plaques and tangles the more dysfunction associated with $\mathrm{AD}$ (McCance \& Huether, 2006).

\section{Vascular Dementia}

Multi-infarct dementia is a common form of dementia and is thought to be a combination of: 1) vascular mild cognitive impairment, 2) multi-infarct dementia, 3) vascular dementia due to a strategic single infarct (affecting the thalamus, the anterior cerebral artery, the parietal lobes or the cingulate gyrus), 4) vascular dementia due to hemorrhagic lesions, 5) small vessel disease (which includes vascular dementia due to brain lesions and Binswanger's disease), and 6) mixed Alzheimer's and vascular dementia (Alzheimer's Association, 2008; Alzheimer's Society, 2008).

Vascular lesions can be the result of diffuse cerebrovascular disease or focal lesions (or a combination of both, which is what is observed in the majority of cases). Mixed dementia is diagnosed when patients have evidence of AD and cerebrovascular disease, either clinically or based on neuroimaging evidence of ischemic lesions (Alzheimer's Association, 2008; Alzheimer's Society, 2008).

\section{Lewey Body Dementia}

Lewy Body Dementia (LBD) exhibits clinical overlap between Alzheimer's disease and Parkinson's disease (McCance \& Huether, 2006). Lewy bodies present as round masses that displace other cell components (Alzheimer's Association, 2008). There are two types: classical (brain stem) Lewy bodies and cortical Lewy bodies. Conventional Lewy bodies are eosinophilic cytoplasmic enclosures that consist of dense cores surrounded by halos of 10-nm wide radiating fibrils (McCance \& Huether, 2006), the 
primary structural component of which is alpha-synuclein, whereas a cortical Lewy body is less well-defined and lacks the halo (McCance \& Huether, 2006). When Lewy body inclusions are found in the cortex, they often co-occur with Alzheimer's disease including neurofibrillary tangles (abnormal tau protein) and senile plaques (deposited beta-amyloid protein) (Alzheimer's Association, 2008; Alzheimer's Society, 2008).

Within LBD, the loss of cholinergic (acetylcholine-producing) neurons is thought to account for the degradation of cognitive and emotional functioning as in AD, while the loss of dopamine-producing neurons is thought to account for the degradation of motor control as in Parkinson's disease (McCance \& Huether, 2006).

\section{Differentiation between Dementia and Delirium}

Nursing literature often uses the terms cognitive impairment, dementia, delirium, and confusion. This study is concerned with nursing home residents with a diagnosis of dementia, including Alzheimer's disease. The American Psychiatric Association defined dementia as the "loss of intellectual abilities (medically called cognitive function) of sufficient severity to interfere with social or occupational functioning" (Maslow \& Mezey, 2008; World Health Organization, 2006). Intellectual abilities include memory and learning, attention, concentration and orientation, thinking (e.g., problem solving, abstraction), calculation, language (comprehension, word finding), and geographic orientation. According to the World Health Organization (2006), "Dementia leads to a loss in all [emphasis added] of these cognitive abilities ... . Dementia is a loss of multiple components of intellectual function ... . Contrary to popular belief, loss of memory is not the only deficit in dementia." For Bjoro and Herr (Bjoro \& Herr, 2008), dementia involves the development of multiple cognitive losses, loss of language, ability to recognize or identify objects, and executive function. In other words, dementia results in a significant loss of intellectual abilities severe enough to interfere with social or occupational functioning.

Dementia and delirium should be considered different diagnoses (Beatty, 2006), a point summarized well by Herr and Garand (2001, p. 463) who define delirium as "acute confusion" and dementia as "chronic confusion." For Barrie (2002, p. 29), dementia is a worsening of intellectual function leading to a decline in the ability to perform activities of daily living and the most common cause $(60 \%)$ of dementia is Alzheimer's disease often called senile dementia. The Geriatric Research Group (n.d.) offers another definition: "[Dementia is] a common clinical syndrome characterized by decline in cognitive function from previously attained intellectual level that is sustained for months or years." Other causes of dementia include vascular dementia 10\%, and Pick's disease, Parkinson's disease, and Cruetzfeldt-Jacob disease cause a small fraction of cases. 


\section{PAIN AND DEMENTIA}

\section{Determining the Presence of Pain in Severe Dementia}

Questions have arisen as to whether Alzheimer's disease alters the processing of pain by the brain. Individuals with DAT receive fewer analgesics and report less pain than cognitively intact controls (Cook, Niven, \& Downs, 1999; Farrell, Katz, \& Helme, 1996; Frampton, 2003). However, it remains unclear if differences in analgesic intake or self report result from impaired communication, impaired memory, or impaired perception of pain resulting from alterations in pain transmission in the brain (Farrell, et al., 1996; Scherder \& Bouma, 1997; E. Scherder, et al., 2003; Scherder, et al., 2005). Questions arise whether the lower level of pain medication is because of less pain or because clinicians are not adequately managing pain in patients with severe DAT.

Evidence does not currently exist determining if the pathways in the brain of individuals with severe DAT are intact (Cole, et al., 2006) and this question must be addressed in order to establish evidenced based nursing care (Algase, 2006; Harvath, et al., 2006).

In 1990, functional mapping of the human brain using venous blood oxygenation level-dependent (BOLD) magnetic resonance imaging contrast was developed (Ogawa \& Lee, 1990; Ogawa, Lee, Nayak, \& Glynn, 1990). The BOLD contrast relies on changes in deoxyhemoglobin levels in the blood as the endogenous magnetic contrast agent (Ogawa, et al., 1990). This means that changes in deoxyhemoglobin levels in the brain cause changes in the MRI signal leading to functional brain mapping or fMRI (Ogawa \& Lee, 1990) and this mapping can describe acute pain in the brain (Davis, 2006).

Pain is a subjective experience with sensory-discriminative, affectivemotivational, and cognitive-evaluative components (Melzack \& Casey, 1968). Each of these components of pain is regulated by lateral and medial pain pathways in the brain. The location, intensity, and quality of pain are modulated by the lateral pain system consisting of the spinothalamic tract ascending from the ventro-posterior lateral thalamus onto the primary and secondary cortices (Bornhovd, et al., 2002; Cole, et al., 2006). The medial pathway, a second major pain pathway, branches at the medulla and ascends via the medial thalamus to the hypothalamic nuclei, limbic regions (cingulate cortex), insula cortex and then onto the prefrontal areas which are involved in the control of emotion, arousal, and attention (Bornhovd, et al., 2002; Cole, et al., 2006; Craig, n.d.; Davis, 2006). The medial pathway is believed to mediate the unpleasant, affective dimension, and the response to noxious stimulus (Bornhovd, et al., 2002; Price, 2000; Treede, Kenshalo, Gracely, \& Jones, 1999). Further evidence from fMRI (Thompson, Hayashi, de Zubicaray, \& Jones, 2003) and pathology (Rub, Del Tredici K, Del Turco, \& Braak, 2002) suggests that the neurodegenerative changes in DAT affect the medial pain system and yet the lateral pain tract is preserved (Scherder \& Bouma, 1997, 2000).

These findings suggest that individuals with DAT have pain, but may not be able to express it. Research among cognitively intact individuals using fMRI has been able to discern between lateral and medial pain pathways demonstrating sensory and emotional pain perception (Bingel, et al., 2002; Bornhovd, et al., 2002). This means that very 
severely cognitively impaired older adults (CIOA) may be able to feel the pain but be unable to verbalize or express it through physical behaviors.

The prevalence of painful conditions increases in clinical settings (Hutt, Pepper, Vojir, Fink, \& Jones, 2006; Marzinski, 1991; Scherder, Bouma, Borkent, \& Rahman, 1999) and administration of analgesic medication decrease as cognitive impairment increases (Cook, et al., 1999; Frampton, 2003; Herr, Mobily, Kouhout, \& Wagner, 1998; Monroe, 2010; Scherder \& Bouma, 2000). This decrease in medication occurs despite the fact that the pain threshold does not differ between mild and moderately CIOA and the intact (Cole, et al., 2006). Gibson and colleagues (2001) used EEG to show that peak amplitude CNS activated evoked potentials are not diminished among verbally communicative subjects with DAT. A limitation of EEG studies is that while cortical processing of noxious stimulus is present, spatial resolution is not possible, limiting the conclusions about how the disease may alter pain-related CNS processing (Cole, et al., 2006). Cole and colleagues (2006) used fMRI to study the pain pathways among verbally communicative individuals with mild to moderate DAT and found that both lateral and medial pain pathways were preserved.

\section{Current Theories Explaining Decreased Pain in Persons with Dementia}

Farrell et al (1996) suggested that language and memory problems might confound reports of pain. Scherder et al (2003) proposed that the neuropathology associated with dementia changes the experience of pain through interruption of neurological transmission. A second neuropathology theory is that the formation of toxic mediators results in out of control inflammatory responses potentially inhibiting or destroying transmissions (Mulugeta, et al., 2008). Damage to different areas of the brain has been associated with both increases and decreases in pain intensity and effect (Melzack \& Wall, 1988) and different types of dementia may be associated with different types of pain experience (Scherder, Sergeant, \& Swaab, 2003). The theory of altered autonomic nervous system response has been studied. Cognitively impaired individuals showed blunted heart rate and blood pressure in response to noxious stimuli compared to matched controls (Benedetti, et al., 1999; Rainero, Vighetti, Bergamasco, Pinessi, \& Benedetti, 2000). However, there were no differences between groups at more intense levels of stimulation (Rainero, et al., 2000). Much of this work has been conducted on acute pain and presently there is not sufficient empirical evidence to support any one theory.

\section{PAIN IN COGNITIVELY IMPAIRED NURSING HOME RESIDENTS}

In 1979, Margo McCaffery (1999, p. 8) defined pain as "Whatever the experiencing person says it is, existing where ever he says it does." The International Association for the Study of Pain provides one widely accepted definition of pain: "An unpleasant sensory and emotional experience associated with actual or potential tissue damage, or described in terms of such damage (International Association for the Study of Pain, 1979). The subjective nature of pain is well characterized by (Johansson, Hamburg, 
Westman, \& Lindergren, 1999, p. 1791). “The main difficulty is that [pain] is a person's private experience, to which no one else has direct access"

Dementia of the Alzheimer's Type (DAT) is the most common cause of dementia (Alzheimer's Association, 2009) The number of persons with DAT in the United States is estimated between 4 to 6 million (Alzheimer's Association, 2009; Hebert, Scherr, Bienias, Bennett, \& Evans, 2003) and current estimates are that DAT cases will grow to 16 and 17 million by the year 2050 (Alzheimer's Association, 2009; Hebert, et al., 2003). Beatty (2006) reports that $10 \%$ of adults over the age of 65 and $50 \%$ over the age of 90 have dementia, while Chung (2006) estimated that $4-12 \%$ of older adults have dementia and/or cognitive impairment (CI).

Many older adults do not receive adequate pain management. Between $40 \%$ and $80 \%$ of community-dwelling older adults (Pahor, et al., 1999; Woo, Ho, Lau, \& Leung, 1994) and $16 \%$ and $25 \%$ of nursing home residents (Feldt, Ryden, \& Miles, 1998; Horgas \& Tsai, 1998; Lichtenberg \& McGorgan, 1987) receive no pain medication. Bernabei and colleagues (1998) found that $25 \%$ of elderly patients who reported daily pain received no analgesics.

Cognitively intact individuals can report their pain and nurses can then intervene. However, we have known for several years that individuals with mild, moderate, or severe cognitive impairment present specific assessment and management problems for nurses (Beck, et al., 1998; Happ, 2000; Harvath, 1994; Kolanowski, Litaker, \& Buettner, 2005) with many individuals unable to self-report pain (Feldt, et al., 1998; Ferrell, Ferrell, \& Rivera, 1995; Hadjistavropoulos, Craig, Martin, \& et al., 1997; Horgas \& Miller, 2008; Tsai, et al., 2008) For example, Weiner (1998) reported that only 30-50\% of adult day care participants with mild and moderate CI could report pain. Self-report becomes impossible as dementia progresses because individuals lose the ability to communicate.

Assessment using behavioral markers becomes unreliable among individuals with severe CI (Gagliese, 2001; Herr, Bjoro, \& Decker, 2006; McCann, Gilley, Hebert, Beckett, \& Evans, 1997; Monroe \& Carter, 2009) because severe CI blunts behaviors (Beck, et al., 1998; Monroe \& Carter, 2009; Reisberg, 1984; Stevenson, Brown, Dahl, Ward, \& Brown, 2006). Assessment relaying on verbal reports becomes unreliable because severe CI blunts speech (Farrell, et al., 1996; Herr, et al., 2006). Therefore, nurses do not have clear evidence-based methods to assess and manage pain in the very severely cognitively impaired older adults and evidence based practice is necessary in order to sustain the profession of nursing (Algase, 2006).

Drawing generalizations from the nursing literature with regard to pain assessment and gauging a resident's mental status is problematic, however, since few authors accurately distinguish dementia, CI, and CI without dementia. For example, Ferrell, Ferrell, and Rivera (1995, p. 597) comment that "Cognitive impairment (dementia or delirium) is a substantial barrier to pain assessment in this population." Here the authors imply that $\mathrm{CI}$ is equivalent to dementia or delirium, when in fact $\mathrm{CI}$ is one 
facet of a differential diagnosis of dementia. Therefore, it would be useful to provide specific definitions of those conditions pertinent to this study, CI and dementia.

\section{HISTORY OF HOSPICE}

Dr. Cicely Saunders began modern hospice at St. Christopher's near London in the 1960's as the first program to use aggressive pain management for dying individuals. Dr. Saunders believed in effective symptom control, caring for the individual, and family (Marx, 2007; Parham, 2002).

In 1963, Dr. Saunders visited Yale University where she presented her model to a group of healthcare professionals including the Dean of the Yale School of Nursing, Florence Wald. Dr. Wald was so impressed she began working to bring hospice to the United States (Parham, 2002). During this time, Elisabeth Kubler-Ross published On Death and Dying based on hundreds of interviews with dying patients. Kubler-Ross believed that individuals had the right to die at home. Ultimately through their efforts, Hospice came to the United States in 1974 located in New Haven, Connecticut and in 1977 the National Hospice Organization (NHO) was founded (Parham, 2002).

\section{ASSESSING PAIN IN NURSING HOME RESIDENTS WITH COGNITIVE IMPAIRMENT}

\section{Instruments}

The Discomfort Behavior Scale (DBS) (Stevenson, et al., 2006) was developed as an alternative to self-report and surrogate pain ratings for older adults with cognitive impairments. The DBS is a 17-item instrument derived from assessment items on the Minimum Data Set (MDS) 2.0 (U. S. Department of Health and Human Services, 2000a) that address behaviors that may indicate discomfort related pain. The MDS is a comprehensive tool that is used to assess all residents in U.S. nursing homes. The assessment includes demographic and diagnostic variables, as well as clinical, functional, psychosocial, and cognitive assessments. Full MDS assessments are required the time of admission and on the annual anniversary of admission. Shorter assessments are completed quarterly and following significant changes in the resident's status (U. S. Department of Health and Human Services, 2000a). Clinicians and care providers should be aware of biases and inconsistencies occurring from surrogate pain ratings (Engle, Graney, \& Chan, 2001; Horgas \& Dunn, 2001) such as those required for the initial MDS assessment, the State of the Art Review of Tools for Assessment of Pain in Nonverbal Older Adults (as cited in Herr, Bursch, Miller, \& Swafford, 2010). This means that the reliability of the DBS is dependent on the potential variability inherent in the MDS.

Initial conceptualization of the DBS was developed with four experts in pain assessment in cognitively impaired older adults reviewing the content validity of the

DBS. Item construction was taken from specific MDS data believed to be behavioral 
indicators of discomfort and potentially discomfort related pain. Content validity was established by reviewing 20 MDS items; 8 from section E1 (indicators of depression, anxiety or sad mood), 10 from section E4 (indicators of behavioral problems such as wandering or resisting care), and 2 from section G1 (self performance such as ability to walk) (Herr, Bursch, \& Black, 2008; Stevenson, et al., 2006). There was 100\% agreement on 19 items and 2 other items related to walking were dropped because they would bias non-mobile residents (Herr et al., 2008).

Next, exploratory (EFA) and confirmatory (CFA) factor analysis were conducted to confirm single discomfort factor dimension. This single dimension was then confirmed in a third sample to confirm the DBS score (Stevenson et al., 2006). EFA demonstrated a single discomfort dimension with a goodness of fit .068. Eigenvalue structure indicated $42.4 \%$ of the variance explained by the single discomfort dimension (Herr, et al., 2008; Stevenson, et al., 2006). CFA with second sample supported the construct of a single discomfort dimension with $\mathrm{CFI}=0.977$, TLI $=0.974$, and RMSEA $=0.068$ (Stevenson, et al., 2006). The third sample used to test the model demonstrated good fit with CFI $=$ $0.955, \mathrm{TLI}=0.955$, and RMSEA $=0.087$.

Composite reliability of the DBS was .98 , with a Chronbach's alpha of .77 and a shared variance of .76 (Stevenson, et al., 2006) indicating that only $24 \%$ of the average variance is related to error (Herr, et al., 2008; Stevenson, et al., 2006). Interrater or Intrarater reliability was not reported in the original study. The authors found each item in the DBS to be tau equivalent with good internal consistency (Stevenson, et al., 2006). The DBS is scored from $0-102$ and factor analysis showed that the DBS is able to discern a single discomfort dimension (Stevenson, et al., 2006). The original study ( $\mathrm{N}=$ $29,120)$ was a large epidemiologic study of cognitively impaired individuals in Wisconsin, USA using the MDS 2.0 (Stevenson, et al., 2006).

Stevenson and colleagues (Stevenson, et al., 2006)compared DBS scores with categorical Cognitive Performance Scale (CPS) scores. The CPS is a reliable and valid measure of cognitive decline that also uses specific MDS items (Paquay, et al., 2007). The CPS is scored from 1 (borderline intact) to 6 (very severe impairment). Stevenson and colleagues studied moderate to very severe impairment (CPS $3-6)$ and found that DBS scores increased with increasing levels of cognitive impairment, except for the highest level of impairment (CPS =6) and hypothesized that severe CI may blunt the outward signs of discomfort (Stevenson, et al., 2006).

The Cognitive Performance Scale (CPS) (Morris, et al., 1994) was developed from five MDS items and is reported both reliable and valid when an individual is trained on its use (Paquay, et al., 2007). The CPS is scored from 1 to 6 indicating borderline intact to very severe impairment. Wu and colleagues (2003) quantified the severity of cognitive impairment with the CPS into three categories, no or mild CI (0-1), moderate CI (2-3), and severe CI (4-6). They reported that scores of 4-6 have been reported to correlate with a MMSE score of $<10$, indicating severe CI while CPS scores of 5 and 6 are equivalent to an MMSE of $<5$ (Hartmaier, et al., 1995; Morris, et al., 1994) indicating very severe impairment. 
Feldt (2000) found that older adults with CI could successfully complete basic verbal pain instruments and that these reports are both reliable and valid, while Stolee, et al. (2005) reported that completion rates on instruments that measure intensity appear to be highest such as the Pain Thermometer and Numerical Rating Scale. For example, they found that $90 \%$ of older adults with mild CI and $100 \%$ of older adults with moderate CI could complete the Faces Pain Scale, the Present Pain Intensity Scale (PPI), and the Memorial Pain Assessment Card (MPAC). Kamel, Phlavan, Malekgoudarzi, Gogel, and Morley (2001) confirmed the usefulness of instruments in assessing a nursing home resident's specific level of pain over asking him or her for a self-report. Among residents given three basic instruments (verbal pain scale, visual analogue scale, and the faces scale), reports of pain increased $50 \%$ over those residents who were simply asked "Do you have pain?"

Verbal descriptor scales such as the PPI are considered advantageous for their easy and quick administration. However, the adjectives used in the scales may hinder the patient from responding, since he or she may not be able to understand or identify the word used as the descriptor of pain (DeWaters, 2003). Freeman et al. (2001) compared residents' results in using the Visual Analogue Scale (VAS), a 0-100 $\mathrm{mm}$ line, and the Faces Rating Scale (FRS), a series of six faces.

The current state of instrument development among non-verbal and severely cognitively impaired individuals is in its infancy. Herr and colleagues (2006) conducted a state of the science review on ten pain behavior instruments. Herr and colleagues'(2006) review showed promise for several instruments and ultimately recommended further testing. Currently there is no behavior instrument with proven reliability and validity for use in the non-verbal and severely cognitively impaired individual (Bjoro \& Herr, 2008).

\section{Methodological Problems Measuring Pain}

The International Association for the Study of Pain (IASP) provides one widely accepted definition of pain which reads, "Pain: An unpleasant sensory and emotional experience associated with actual or potential tissue damage, or described in terms of such damage" (International Association for the Study of Pain, 1979, p. 250). The difficulties in the subjective nature of pain are summed up by Johansson, Hamburg, Westman, \& Lindgren (1999, p. 1791), "The main difficulty is that [pain] is a person's private experience, to which no one else has direct access." McCaffery (1999, p. 8) defined pain as, "Whatever the experiencing person says it is, existing where ever he says it does." If according to these recognized definitions of pain, a person must understand and report pain, then the person must be able to recognize and describe the experience of pain. This is clearly a problem for people with cognitive impairments.

How one interprets his/her own quality of pain is key in establishing reliability and validity in the cognitively impaired elderly person (Ferrell, Stein, \& Beck, 2000). Feldt (2000, p. 14) summarized threats to validity when assessing pain in older persons with CI, "Impaired verbal skills and the ability to abstract concepts further obstruct assessment in pain for this population." According to Ferrell et al. (2000, p. 1669), "Valid 
and reliable assessment of pain relies on individual patient interpretations and selfreport." Additionally, Feldt (2000) pointed out decreased reliability inherent in many pain assessment tools used in the cognitively impaired that rely on memory of previous painful experiences. Bjoro and Herr (2008, p. 246) stated, "Observational approaches to pain assessment rely on interpretations of behaviors. The inherent subjectivity involved . . . represents challenges to the reliability and validity of pain assessments." As such, there is currently no reliable or valid observational tool recommended for clinical practice (Bjoro \& Herr, 2008).

Pasero and McCaffery (2001) argue that the only reliable information about pain must come from the patient. Hanson et al. (2008) reported that among nursing home residents with CI, $42 \%$ could express pain verbally; Ferrell (1995) found that $62 \%$ of nursing home residents with mild and moderate CI were able to report pain, and $83 \%$ could use one of five pain instruments (Ferrell, et al., 1995). The challenge, therefore, is to find a reliable and valid instrument that will be useful in residents with CI who are in many instances nonverbal.

\section{Methodological Problems Measuring Cognitive Impairment}

The Mini-Mental State Examination (MMSE) is the most frequent research and assessment tool for measuring CI and measuring cognitive status (Chopra, Cavalieri, \& Libon, 2007; Tombaugh \& McIntyre, 1992). There are inconsistencies and improper usage of the MMSE found in research literature.

The MMSE was not designed to be the sole determinant of dementia and is intended to be used only as a screening device for impairment (Chopra, et al., 2007; Decker \& Perry, 2003; Folstein, 1975; Teng \& Chui, 1987; Tombaugh \& McIntyre, 1992; Weiner, 1999). Screening means that dementia likely exists. The MMSE is not reliable in persons with less than an eighth grade education and in persons who are not fluent in spoken English (Tombaugh \& McIntyre, 1992). Heye (1997, p. 136) pointed out that screening for CI can be facilitated with the MMSE but the client must be able to speak, hear, and see. Weissman and Matson (1999, p. 34) shared concerns with CI that would directly affect administration of the MMSE related to hearing, visual impairment, language, attention span, and cognitive ability affecting the assessment process. Lehmann \& Rabins (1999, pp. 180-181) stressed CI should only be a part of the mental state examination: "The complete mental status examination, however, always [emphasis added] includes attention to the following areas: general appearance, speech, mood, suicidal ideation, abnormal thought content, and cognitive assessment." The MMSE only touches on a few of these components, speech and cognitive status.

The MMSE is probably the most popular tool for measuring cognitive status (Chopra, et al., 2007), but it was designed to be used only as a screening device for levels of impairment (Chopra, et al., 2007; Folstein, 1975; Teng \& Chui, 1987; Tombaugh \& McIntyre, 1992). There are additional issues to be addressed when using the MMSE as a research tool in assessing nursing home residents with CI: their educational level, sensory status, and language fluency, for example. Some researchers, such as Tombaugh and 
McIntyre (1992) have suggested that comparing MMSE scores across multiple studies may be difficult because a variety of ranges of impairment have been used. An example may be 26-30 no CI, 21-25 MCI, 16-20 moderate CI and 15 or less indicating severe CI.

\section{SUMMARY}

In the U.S., $25 \%$ of adult deaths each year now occur in nursing homes (30\% in the first year), and the prevalence of dementia and pain or painful conditions may be as high as $82 \%$ in these settings. This means that approximately 800,000 people die in nursing homes and nearly 650,000 of these have dementia prior to demise. In addition, more than $50 \%$ of nursing home residents have pain and as many as $90 \%$ of those with cancer have pain. In 1989, the federal government extended hospice benefits to residents in nursing homes and in 1996 established diagnostic guidelines for admitting persons with dementia, but as shown above a large majority of hospice-eligible residents, especially those with CI, never benefit from its services. A major goal of this study is to document the impact of hospice on the terminally ill nursing home resident with CI who suffers significant pain and thus diminished quality of life. Its primary research question involves the identification of differences in pain assessment, pain management, and medication administration between two populations: nursing home resident with CI who received hospice services and residents with $\mathrm{CI}$ who did not. Instruments used to measure pain in persons with cognitive impairment are in the infancy stage of development. Most instruments rely on behavioral discomfort or pain cues. Determining the feasibility of using behavioral instruments among the more severely cognitively impaired is a secondary goal of this study. 


\section{CHAPTER 3. HOSPICE IN U.S. NURSING HOMES: BENEFITS AND BARRIERS*}

\section{INTRODUCTION}

There is general consensus among experts that nursing home residents in the United States do not receive adequate pain management (Herr \& Decker, 2004) or highquality palliative care, especially symptom management at the end of life (Duncan, Forbes-Thompson, \& Bott, 2008; Hanson, Sengupta, \& Slubicki, 2005). Hospice can positively benefit end-of-life symptom management where about a fourth of adult deaths in the U.S. now occur (Ersek \& Wilson, 2003; Hanson, Sengupta, et al., 2005). Almost $50 \%$ of nursing home residents have dementia (Magaziner, et al., 2000) and the prevalence of pain or painful conditions is estimated to be between $49 \%$ and $83 \%$ among residents with dementia (Bjoro \& Herr, 2008). This means that of the approximately 800,000 residents in the U.S. who die in nursing homes, over 400,000 have dementia and 650,000 have pain. Enrollment in hospice at the end of life in the nursing home is one way to improve care for these residents. Currently, $2 \%$ of residents are enrolled in hospice upon admission (Parker-Oliver, Porock, Zweig, Rantz, \& Petroski, 2003) while $6 \%$ (Miller, Mor, \& Teno, 2003) of nursing home residents are enrolled in Hospice prior to death. Finding ways to improve hospice enrollment among nursing home residents, especially those with dementia and pain, remains a clear challenge.

In 1996, Medicare hospice services were extended to terminally ill older adults with severe cognitive impairments (Cherney, 2008). These new guidelines covered many nursing home residents who were not previously eligible for hospice. Countless older adults with severe cognitive impairment, especially those with Alzheimer's disease, live and die in nursing homes which by 2003 was the fifth principal cause of death among individuals over the age of 65 in the U.S. (Mitchell, 2007). Hospice services can offer nursing home staff and families support while simultaneously helping manage pain, providing comfort, and easing the transition to death in older adults with cognitive impairment.

Since the approval in 1989 of a Medicare Hospice Benefit (MHB) (Centers for Medicare and Medicaid, 2008; Munn, et al., 2006), nursing homes have been able to offer a wide range of hospice services to dying residents (Figure 3-1). However, fewer than half of residents who are hospice eligible actually receive the benefit (Munn, et al., 2006). Miller and colleagues (2002), found that while $24 \%$ of nursing home residents were hospice eligible, only $6 \%$ of dying residents used the benefit, while Evans (2002) reported that only $1 \%$ of nursing home residents use the benefit, and fully $70 \%$ of all nursing homes have no resident enrolled in hospice (Keene \& Thompson, 2008; Petrisek $\&$ Mor, 1999). These studies show an under use of hospice in nursing homes.

*Reprinted with permission from Monroe, T \& Carter, M. (2010) Hospice care in US nursing homes: benefits and barriers. European Journal of Palliative Care, 17(3),144149. 


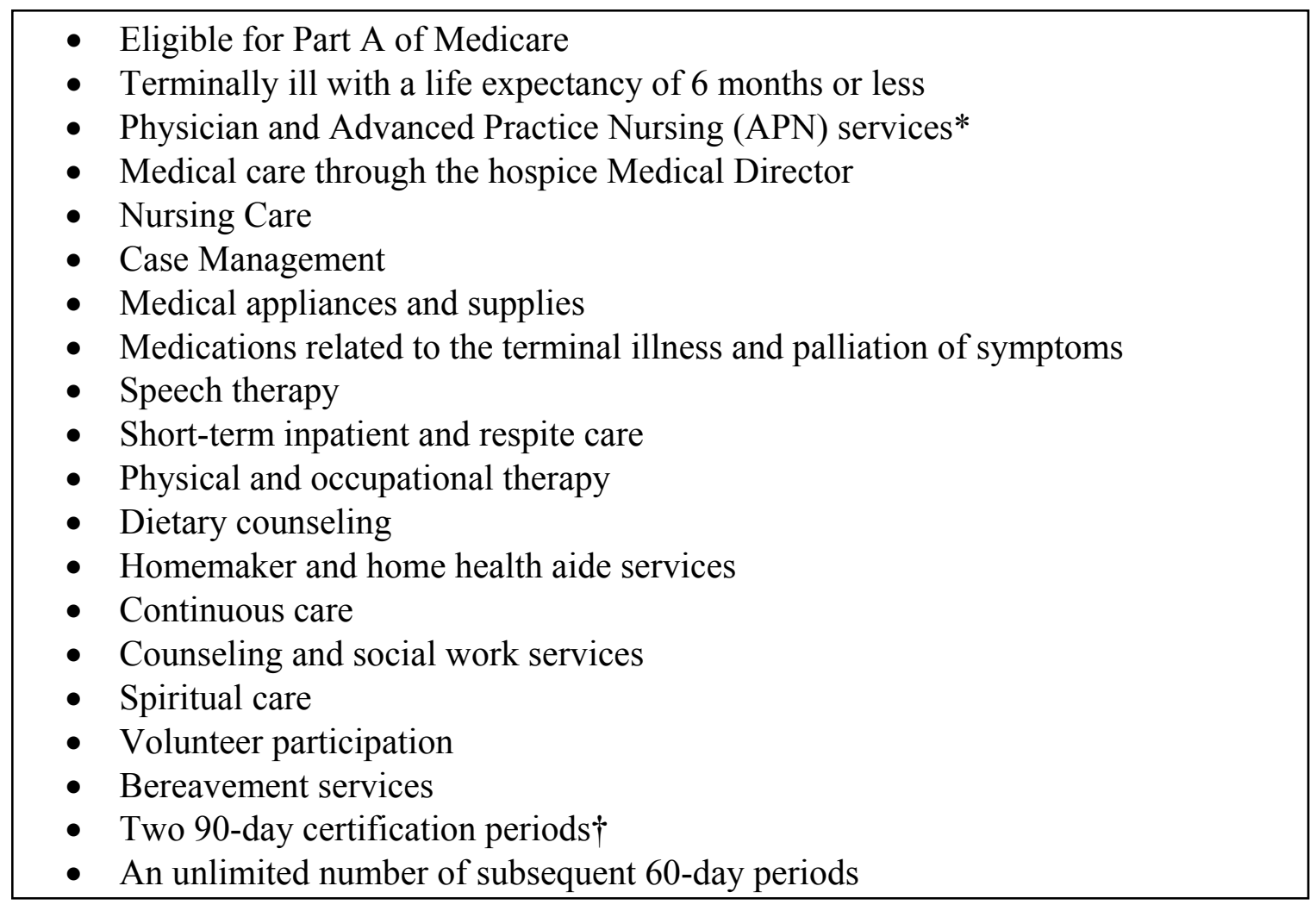

Figure 3-1 The Medicare Hospice Benefit

* The first 90-day hospice certification must be approved by the beneficiary's attending physician and the hospice medical director. The remaining 60-day periods require only 1 physician.

$\dagger$ In 2004, the US Congress and Centers for Medicare and Medicaid Services developed new provisions in hospice care as a result of the Medicare Act of 2003: the definition of attending physician was changed to include nurse practitioners (NPs); however, nurse practitioners cannot certify a patient's terminal illness as the physician.

Adapted with permission from Centers for Medicare and Medicaid (2008) The Medicare hospice benefit. Retrieved November 24, 2008, from

http://www.medicare.gov/publications/Pubs/pdf/02154.pdf 
The purpose of this manuscript is to provide a broader understanding of hospice in nursing home settings by detailing the multiple benefits of its end-of-life care. Hospice care for nursing home residents with dementia and/pain is better when measured by documentation of assessment and administration of medications, documentation of receipt of alternative therapies, and documentation of fewer prescribed and administered inappropriate medications for use in the elderly. Hospice use is less costly to the total health care dollar because it decreases futile care at the end of life and reduces unnecessary hospitalizations. Barriers to hospice use in nursing homes are detailed, followed by a discussion of what nurses and others can do to increase hospice enrollment among nursing home residents.

\section{BENEFITS OF HOSPICE IN NURSING HOMES}

\section{Better Pain and Symptom Management}

Nursing home residents receive several benefits from using hospice. Pain management has been a concern among nursing home residents for nearly 30 years (Ferrell, Ferrell, \& Osterweil, 1990). More recently, investigators found that $86 \%$ of dying nursing home residents had pain and $53 \%$ of those had moderate to severe pain (Reynolds, et al., 2002). Hospice can provide several benefits for nursing home residents and pain management appears to be one advantage. One study showed that longer-stay ( 7 days or more) nursing home residents in hospice had a greater ( $\mathrm{AOR}=5.4 ; 95 \% \mathrm{CI} 1.3$, 21.7) likelihood of receiving an opioid and a greater $(\mathrm{AOR}=2.7 ; 95 \% \mathrm{CI} 0.9,7.7 ; p=$ 0.07 ) likelihood of receiving an opioid twice a day (Miller, et al., 2003). Other researchers found that residents enrolled in hospice were more likely to receive opioids for pain and two times more likely to have a documented pain assessment ( $\mathrm{Wu}$, et al., 2003). Miller et al., (2002), reported the use of analgesic medication among hospice enrollees in nursing homes was $50 \%$ greater than non-hospice enrollees (OR $0.57 ; 95 \%$ CI $0.45,0.7)$ Munn and colleagues (2006) compared nursing home residents enrolled in hospice and those who were not $(\mathrm{N}=124)$. They found $85 \%$ of nursing home residents had moderate to severe pain compared to $52 \%$ of those enrolled in hospice $(p<.05)$ and $82 \%$ of hospice enrolled residents received pain medications compared to $50 \%$ of those not enrolled $(p<.05)$. Nursing home residents enrolled in hospice experience a $93 \%$ $(95 \%$ CI, $1.56-2.38)$ greater likelihood of having an attempt to manage documented pain (U. S. Department of Health and Human Services, 2000b).

Researchers (2006) found that alternative pain management strategies such as ice packs and massage were more often used among hospice residents $(26 \%$ vs. $6 \%, p=$ $.004)$ and hospice residents were more likely to have assistance with eating (89\% vs. $63 \%, p=.01)$ and oral hygiene $(96 \%$ vs. $78 \%, p=.03)$. A meta-analysis of 19 hospice/palliative care studies revealed that pain was mildly better managed by hospice/palliative care teams $(\mathrm{OR}=0.38 ; 95 \% \mathrm{CI} 0.23-0.64)$ and all other symptoms were moderately better managed by hospice/palliative care teams $(\mathrm{OR}=0.51 ; 95 \% \mathrm{CI}$ $0.30-0.88$ ) (Higginson, et al., 2003). Hospice is better at managing pain in nursing home 
residents when pain management is measured by residents receiving opioids or other pain medications, or by the use of alternative therapies.

Better overall pain and medication management are recognized benefits among residents using hospice. One study reported that hospice residents received fewer inappropriate medications as recommended by the American Medical Director's Association ( $\mathrm{OR}=0.65$; 95\% CI 0.52-0.80, (Miller, et al., 2002).

Pain management may be better among all residents when hospice is used in the facility, a phenomenon identified as the hospice effect. One possible cause is that nurses are reminded to assess and treat pain when they see hospice personnel in the building; their mere presence acts as a cue to other staff to manage the pain of non-hospice residents. Pain assessments were more likely in non-hospice individuals who resided in facilities where hospice was present (Wu, et al., 2003). Another example of the hospice effect is seen in cost savings to health care. Researchers found that non-hospice nursing home residents hospitalizations decrease as hospice enrollment increased (U. S. Department of Health and Human Services, 2000c).

Residents enrolled in hospice $(\mathrm{N}=1,982)$ were compared with those who were $\operatorname{not}(\mathrm{N}=6,392)$ (U. S. Department of Health and Human Services, 2000c). Detection of daily pain (as documented on the last MDS prior to death) was different among the groups. Residents enrolled in hospice with cancer and no dementia $(n=430)$, had daily pain $(28.1 \%)$ and among those with cancer and dementia $(n=717), 16.0 \%$ experienced daily pain. Residents not enrolled in hospice with a diagnosis of cancer and no dementia $(n=1,529)$ had a pain detection rate of $16.8 \%$ and those not enrolled in hospice with a diagnosis of cancer and dementia $(n=2,293)$ had a pain detection rate of $8.9 \%$ (U. S. Department of Health and Human Services, 2000c). These same researchers found that among residents with dementia enrolled in hospice $(n=394)$ pain was detected in $11.4 \%$ compared to $5.0 \%$ among residents with dementia not enrolled in hospice, and for all "other" diagnoses enrolled in hospice $(\mathrm{n}=441)$ pain was detected $17.5 \%$ of the time compared to a $7.8 \%$ pain detection rate for all "other" diagnoses non enrolled in hospice (U. S. Department of Health and Human Services, 2000c). This means that while hospice enrollees have better pain detection across the board, those residents diagnosed with cancer or cancer and dementia that are enrolled in hospice experience more frequent pain detection resulting in better quality of care.

\section{Financial Benefits}

A final benefit may be evident in the costs savings to the health care system. Greater hospice enrollment may help ease the burden on the U.S. healthcare system, since health utilization costs decrease when residents are not constantly transported to and from the hospital and do not use acute care facilities (Susan L. Mitchell, et al., 2004).

Investigators found almost half (43.7\%) of nursing home residents compared to $31.5 \%$ ( $p$ $=.001$ ) with dementia (CPS score $=5$ or 6 ) were hospitalized at least one time during the last 90 days of life (Susan L. Mitchell, et al., 2004) and decreasing just one hospital day per Medicare beneficiary can save the US health care system millions of dollars 
(Kronman, Ash, Freund, Hanchate, \& Emanuel, 2008). This means that residents with dementia and cognitive impairments are transported to hospitals more frequently (Teno, et al., 2004), when available hospice care can help relieve pain and provide support to the resident and family. Researchers found that more primary care visits in the year preceding death equated to fewer hospitalized days prior to death possibly attributed to increased opportunities to prevent medical complications and coordinating palliative home care (Kronman, et al., 2008).

According to the U.S. Department of Health and Human Services (2000c), nursing home residents who use hospice are significantly less likely to be hospitalized in the last 30 days of life than those residents who do not (12.5\% vs. $41.3 \%)$, in the last 90 days $(24.5 \%$ vs. $53 \%)$, and in the last 6 months (39.8\% vs. $61.6 \%)$. More specifically, residents who use hospice save Medicare an average of $\$ 2309$ per hospice user when compared to non-hospice decedents $(p=.001)$ (Taylor, Ostermann, Van Houtven, Tulsky, \& Steinhauser, 2007) and the U.S. Department of Health and Human Services (2000c) found the reduction in hospitalizations in the last 30 days translated into acute medical care savings of $\$ 2909$ per resident.

Investigators found that $25 \%$ of hospice users were enrolled for less than one week (Taylor, et al., 2007; U. S. Department of Health and Human Services, 2000b) and $50 \%$ are enrolled less than 30 days (U. S. Department of Health and Human Services, 2000c). Individuals with cancer save Medicare the most (\$7000) while other primary conditions save $\$ 3500$ noting that after 6 months of hospice, the savings to Medicare cease but do not increase over the non-hospice users (Taylor, et al., 2007). Residents who received information about palliative care and subsequent assistance enrolling in hospice had fewer acute care admissions (mean 0.28 vs. $0.49 ; p=.04$ ) and experienced fewer hospitalized days (mean: 1.2 vs. 3.0; $p=.03$ ) (Casarett, et al., 2005). Thus, efforts to increase short-stay hospice offer a greater opportunity to save Medicare dollars over attempts to reduce long-stay hospice (Taylor, et al., 2007; U. S. Department of Health and Human Services, 2000b) and increasing the length of enrollment in 7 out of 10 nursing home residents would greatly increase savings (Taylor, et al., 2007). Hospice could also help the financial picture of the nursing home in that the facility would be paid the daily rate rather than lose this payment during the resident's hospitalization.

\section{BARRIERS TO HOSPICE USE}

\section{Patient and Family Barriers}

In some situations, a family's culture and religion may influence their decisions concerning hospice enrollment for their loved one. According to Jablonski and Wyatt (2005), Hispanic and African American families generally favor life-sustaining measures over palliative care, which may conflict with caregivers' attempts to offer pain relief. Certain spiritual and religious traditions, such as a belief in God or higher power, may help individuals cope with the dying process and associated pain. The family may believe 
that everything that can possibly be done must be done and life sustained at all costs even when this increases suffering of the resident and the family.

Other resident and family barriers to hospice include patient preferences for lifesustaining treatment, perhaps indicating a lack of understanding by the patient and family about the terminal nature of the diagnosis (Casarett, van Ness, O'Leary, \& Fried, 2006), or perhaps a desire to not surrender to the disease. Casarett and colleagues (2004) found $56 \%$ of patients and families were reluctant to accept the terminal nature of the diagnosis and most (91\%) hospice-eligible older adults did not enroll until late in the course of a 6month illness. Among residents enrolled in hospice, one third had been there less than 2 weeks and one fifth less than 1 week (Dobbs, et al., 2006; Miller, et al., 2003). These studies suggest that in many circumstances, patients are not receiving the full benefit of hospice because of late enrollment. More education on hospice practices, and its provision earlier in the course of a patient's likely terminal illness, would help address these issues. However, the likely reluctance of 'giving up' that is implied by engaging in hospice poses a significant barrier to enrollment.

There are barriers to hospice enrollment that are specific to residents with dementia and/or severe cognitive impairment. One study found only 1 in every 10 persons dying with dementia were enrolled in hospice (Sachs, Shega, \& Cox-Hayley, 2004). This low enrollment is likely the direct result of communication problems between residents and staff and $17 \%$ of nursing home nurses believe that hospice staff do not have the skills to care for residents with dementia (Tarzian \& Hoffmann, 2006). This finding is interesting given that $59 \%$ of nursing home residents using hospice experience some cognitive impairment (Reynolds, et al., 2002). Mitchell, Kiely et al., (2004) reported that residents with cognitive impairments who are admitted to nursing homes had more functional disability, behavior problems, and tube feedings likely contributing to lower hospice enrollment. The authors also found that this cohort is often not recognized as terminally ill, with very infrequent (5.4\%) referrals to hospice (Susan L. Mitchell, et al., 2004). Communication difficulties between residents and nurses and difficulty recognizing deteriorations in health make enrolling residents with dementia difficult. Educating staff and family on the benefits of hospice use among residents with dementia could help to increase enrollment. Determining when a resident becomes terminal is not easy.

A majority of hospice nurses $(88 \%)$ and $45 \%$ of nursing home nurses believe that lack of knowledge about hospice on the part of residents and families is a barrier to hospice use (Tarzian \& Hoffmann, 2006). Hospice enrollment increased after a brief structured interview between a clinician and nursing home residents and their families. The interview included information about the hospice philosophy and appropriateness for the resident. Within 30 days, $20 \%$ of the intervention group reported enrollment, versus $1 \%$ for the nonintervention group $(p<.001)$ (Casarett, et al., 2005). The resident's physician initiated hospice if appropriate after receiving a data sheet suggesting a potential fit for hospice. Another study revealed that $85 \%$ of patients and families decided to enroll in hospice after one conversation (Casarett, et al., 2004). One effective strategy to increase hospice enrollment that can be initiated by nurses or physicians appears to be 
simple communication to residents and families about hospice and its role in end-of-life care.

\section{Nursing Home Staff Barriers}

Lack of knowledge about and familiarity with hospice and palliative care on the part of nursing home staff is one barrier to its full utilization in such settings. A study of nursing home and hospice nurses found that $92 \%$ of hospice nurses and $26 \%$ of nursing home nurses believed that a lack of knowledge about hospice on the part of the nursing home staff was a barrier to hospice enrollment (Tarzian \& Hoffmann, 2006). Symptom relief is a major tenet of palliative care and overall symptom burden is higher among nursing homes than residential care or assisted living facilities $(19.8 \%$ vs. $16.8 \%, p=<$ .001, (Hanson, et al., 2008). Jablonski and Wyatt (2005) explained that the problem of symptom relief in nursing homes may be exacerbated by the large numbers of unlicensed personnel lacking palliative education providing a majority of the care. In one study, nearly $20 \%$ of nursing homes did not provide formal training in end-of-life pain and symptom management and more than $50 \%$ of nursing home administrators believed that educational deficits were the single greatest obstacle to providing quality end-of-life care (Rice, Coleman, Fish, Levy, \& Kutner, 2004). Unfortunately, the study by Hanson and colleagues (2008) found that nursing home staff had no recommendation or suggestion for improving symptom relief of pain $(87 \%)$, dyspnea $(89 \%)$, or cleanliness and oral intake $(90 \%)$ at the end of life. All of these factors may create higher levels of family dissatisfaction with care, greater patient discomfort at the end of life, and increased chances that staff will not recognize a resident's eligibility for hospice.

\section{Organizational and System Issues Barriers}

Another perhaps more determinant barrier is rooted in the core philosophical differences between traditional nursing home care which is on health maintenance, and established hospice practice which is palliative (Table 3-1). These differences are complicated by the documentation system used in nursing homes. The Minimum Data Set (MDS) focuses on restorative rather than palliative care (Evans, 2002; Tarzian \& Hoffmann, 2006) and is required on each admission and quarterly thereafter. For example, the MDS focuses on health and functional indicators (Hoffman \& Tarzain, 2005) and does not promote symptom management such as pain control, dyspnea, end-oflife issues, fatigue, or spiritual needs (Evans, 2002). An illustration of this policy conflict exists where the MDS mandates that evidence of a resident's malnourishment be redressed; however, if the resident is dying decreased food intake may be part of the dying process and prolongation can actually increase suffering (Evans, 2002; Hoffman \& Tarzain, 2005; Tarzian \& Hoffmann, 2006). Clearly, palliative care is not supported by the current MDS and improvements to the documentation system are needed.

The resident plan of care potentially creates a significant barrier to enrollment. Parker-Oliver (2002) found among administrator's and directors of nursing (DON's) ( $\mathrm{N}=$ $60)$ confusion existed over the ultimate responsibility of the care of the resident with 
Table 3-1 Differences in Care between Nursing Homes and Hospice*

\begin{tabular}{|c|c|c|}
\hline Care Characteristic & Nursing Homes & Hospice \\
\hline Curative or Restorative Care & Yes & No \\
\hline Palliative Care & Sometimes & Always \\
\hline $\begin{array}{l}\text { Amount of Technical Care Work } \\
\text { (charting, taking vital signs, } \\
\text { hygienic care, etc.) }\end{array}$ & High & Low \\
\hline $\begin{array}{l}\text { Amount of Relational Care Work } \\
\text { (spiritual or psychological } \\
\text { counseling, listening) }\end{array}$ & Low & High \\
\hline Care Recipient & Resident & Resident \& Family \\
\hline Care Provided by Volunteers & Seldom & Often \\
\hline Grief Counseling & Seldom & Always \\
\hline \multicolumn{3}{|c|}{$\begin{array}{l}\text { *Adapted with permission from Parham, L. (2002). Contrasts in care work: Hospice care } \\
\text { in nursing homes (Doctoral Dissertation). Accessed July 17, 2008, from } \\
\text { http://fs.aleph.fcla.edu/F/5BX3Y1FQMCI2V69V2XU9SVSU1QIYF21959T96J4L8FUB } \\
6 \text { HX532-31842? func=full-set-set\&set_number=002202\&set_entry=000001\&format=999 }\end{array}$} \\
\hline
\end{tabular}


$36 \%$ of respondents believed that the nursing home and hospice were responsible for the palliative plan of care, $18 \%$ identified hospice, and $6 \%$ did not know. Among this same cohort, only $38 \%$ believed they understood how hospice was reimbursed and $15 \%$ believed that hospice and nursing home boundaries were not clear (Parker-Oliver \& Bickel, 2002). Another study of hospice nurses $(\mathrm{N}=69)$ found that one third defined communication/miscommunication as one of the biggest problems working with hospice patients in nursing homes (Parker-Oliver, 2002). This means that lack of understanding about hospice and nursing home plans of care may lead to gaps in care, gaps in reimbursement, and potential liability. For example, the nursing home and hospice may establish two different wound care plans for the same patient. The resident lives in the nursing home making the nursing home liable, not the hospice, since this nursing home is responsible for the overall plan of care.

Staffing shortages (Ersek \& Wilson, 2003) and high employment turnover (Evans, 2002) contribute significantly to low quality end-of-life care (Hanson, Sengupta, et al., 2005; Rice, et al., 2004). Nursing home staff are generally the lowest paid in the industry (Ersek \& Wilson, 2003) and this makes recruitment and retention very difficult. Investigators found turnover rates in Texas nursing homes were $133 \%$ for registered nurses, $108 \%$ for licensed vocational nurses, and $160 \%$ for certified nursing assistants (Kash, Castle, Naufal, \& Hawes, 2006) and many nursing homes in Kansas also experience greater than $100 \%$ turnover for all staff (Clarkin, 2008). Nursing home administrators also experience high turnover. Castle (2001) discovered $43 \%$ of nursing home administrators quit prior to completing one year of employment. Staffing shortages and high attrition make detailed assessments difficult, and most of the care is provided by licensed practical nurses with less education, especially in end-of-life care. This means discontinuity can occur between the hospice plan of care and the nursing home plan of care resulting from frequent staff turnover.

Conflicts between hospice staff and nursing home staff also serve as a barrier to hospice use in nursing homes. Both hospices and nursing homes are regulated by the state and each has a different organizational structure and culture. Hospices provide "relational care" where nursing homes provide "routinized care" (Parham, 2002, p. 14). Relational care is more democratic with the resident and family having more choices and routinized care is very structured and bureaucracy driven (Parham, 2002). As a result, relationships between hospice and nursing homes staff can become strained, negatively impacting the resident's care. Tarzian and Hoffman (2006) found that many nursing home staff believed that hospice staff were not familiar with nursing home policy and believe that most hospice staff rarely did anything that nursing home staff did not do. Another conflict was shared by nursing home nurses feeling like hospice nurses "know everything" and tend to "take-over" rather that work in a collaborative effort (Tarzian \& Hoffmann, 2006). Parker-Oliver (2002) found hospice nurses have the following perceptions about nursing home nurses; $70 \%$ believe "hospice staff come and tell us what to do, yet we are here 24 hours a day", $54 \%$ believe "hospice puts everyone on morphine", and 53\% believe "hospice just lets residents die". 
Financial concerns have been commonly identified as barriers to hospice use, particularly with regard to reimbursement and billing for specific services (Dobbs, et al., 2006; Tarzian \& Hoffmann, 2006). To cite but one example, Medicare's Skilled Nursing Benefit will pay for room and board, whereas Medicare's Hospice Benefit will not. This means that residents using the Medicare hospice benefit must find other resources to pay for room and board including out of pocket, private insurance or Medicaid resulting in a complicated and potentially lower reimbursement to the nursing home (Jablonski \& Wyatt, 2005). A second issue concerns reimbursement methods. Hospice agencies' reimbursement to nursing homes tends to operate more slowly than government healthcare agencies like Medicare and Medicaid (Evans, 2002). For example, if a resident is Medicaid eligible, Medicaid will pay the hospice $95 \%$ or more of the state's daily nursing home rate, and then the hospice will reimburse the nursing home for room and board complicating payment to the nursing home (Parham, 2002). Another reimbursement concern is that nursing homes receive higher payment for rehabilitative rather than palliative care, therefore revenue will be higher in nursing homes not using hospice (Jablonski \& Wyatt, 2005).

\section{Other Barriers}

Difficulty in determining the 6-month window to death, required by Medicare, may serve as another barrier to hospice enrollment (Lorenz, Shugarman, \& Lynn, 2006). Many physicians' are uncomfortable in estimating demise among residents, especially those with dementia (Evans, 2002; Mitchell, 2007), congestive heart failure and chronic obstructive pulmonary disease (Lorenz, et al., 2006) compared to those with cancer who typically follow a predictable trajectory (Lorenz, et al., 2006). For example, one instrument used to establish hospice eligibility for persons with dementia is the Functional Assessment Staging (FAST) scale (Reisberg, 1988). However 40\% of residents in one study could not be evaluated with the FAST scale (Figure 3-2) because their disease progression did not match FAST scale progression (Luchins, et al., 1997). Episodic periods of deterioration and recovery are common in nursing home residents, and this makes determining when the resident is in the final 6 months of life difficult. This means that admission into hospice only need be determined by prognosis and hospice can be renewed if they do not die within six months as long as the resident meets the conditions for enrollment.

\section{WHAT NURSES AND OTHER CARE PROVIDERS CAN DO TO INCREASE HOSPICE ENROLLMENT}

Education and awareness can have positive results on hospice enrollment. Hanson et al., (2005) reported an increase in rates of hospice enrollment from $4.0 \%$ prior to an educational intervention to $6.8 \%$ post-intervention $(4.0 \%-6.8 \%, p=0.01)$. Staff reported an increase from $66 \%$ to $85 \%$ in their confidence to provide palliative care while concurrently increasing hospice enrollment from 35 to 59 residents among the seven nursing homes studied after participating in a 1-day educational program on palliative care. Hospice access is also more likely when a contract exists between the nursing home 


\section{Eligibility criteria for hospice using the FAST scale (must have both)}

1. Functional Assessment Staging (FAST) level of stage 7c or beyond and evidence all components of stages $6 \mathrm{a}-7 \mathrm{c}$

2. The individual must have one of the following associated medical conditions within the previous year*

FAST Stage 1: No objective of subjective difficulties

FAST Stage 2: Subjective reports of forgetting

FAST Stage 3: Decreased job functioning evident to coworkers. Difficulty traveling to new locations

FAST Stage 4: Decreased ability performing complex tasks (e.g., planning dinner for guests, handling finances)

FAST Stage 5: Requires assistance to choose proper clothes for day, season, or occasion

FAST Stage 6a: Cannot dress without assistance occasionally or more frequently

FAST Stage 6b: Cannot bathe without assistance occasionally or more frequently

FAST Stage 6c: Cannot toilet without assistance occasionally or more frequently

FAST Stage 6d: Incontinent of urine occasionally or frequently

FAST Stage 6e: Incontinent of bowel occasionally or frequently

FAST Stage 7a: Speech limited to fewer than 6 intelligible words during an average day $\dagger$

FAST Stage 7b: Speech limited to a single intelligible word during an average day

FAST Stage 7c: Unable to ambulate independently

FAST Stage 7d: Cannot sit up independently

FAST Stage 7e: Cannot smile

FAST Stage 7f: Cannot hold head up independently

Figure 3-2. Determining Hospice Eligibility for Individuals with Dementia

*Associated Medical Conditions (must have one within previous year): Aspiration pneumonia, pyelonephritis or other upper urinary tract infection, septicemia, decubitis ulcer (multiple, stage 3-4), recurrent fever after treatment with antibiotics, eating problems such that fluid or food intake is insufficient to sustain life (or, if tube fed, weight loss $>10 \%$ over prior 6 months or serum albumin $<2.5 \mathrm{~g} / \mathrm{dl}$ ). $\uparrow$ Stage 7a: In some geographical areas of the country, individuals with a FAST stage of $7 \mathrm{a}$ are eligible for hospice (Cherney, 2008).

Source: Adapted with permission from Mitchell, S. L. (2007). A 93-year-old-man with advanced dementia and eating problems. Journal of the American Medical Association, 298(21), 2257-2536. 
and hospice (Rice, et al., 2004). Nurses and health care providers who are themselves better educated on the benefits of hospice can provide education and awareness to residents, their families, and the community positively improving hospice enrollment. Many of these opportunities are currently available on-line (Table 3-2).

Braun and Zir (2005) developed the Appropriateness Care of Residents in Nursing Homes (ACORN) to teach nursing home workers about end-of-life care. Registered nurses and certified nursing assistants (CNAs) participated in the training. ACORN training consisted of 8 interactive one-hour sessions located in 10 nursing homes. Topics included: pain assessment and management, symptom management, advanced directives, cultural issues and dying, and grief support. Pre and postintervention knowledge was significant $(p=.01)$ among CNAs in all five categories measured: comfort, knowledge of death and dying, grieving, facility deals with dying, and pain management. However nurses reported only one area of significant $(p=.01)$ knowledge growth, facility deals with dying. Evidently, ACORN is better at helping paraprofessionals increase their knowledge of end-of-life care. Residents, families, and staff may benefit from an educational intervention such as ACORN. Nursing assistants spend considerable time with residents and educational interventions that target these individuals may well serve residents, families, and facilities. Paying for ACORN or other educational training presents financial considerations for nursing home administrators.

\section{SUMMARY}

To summarize, there are many benefits to hospice use in nursing homes. First pain and non-analgesic medication management is better among hospice enrollees possibly attributed to the increased numbers of professionals participating in care including, nurses, physicians, clergy, and social workers that have training in palliative care. Next, greater symptom recognition and management occurs among residents enrolled in hospice and this dually contributes to increased comfort for residents and better attitudes from the resident and family favoring hospice services. A better relationship between hospice personnel and residents and their families helps each to become more comfortable with the terminal prognosis. Hospice can save significant health-care dollars by reducing unnecessary expenditures associated with unnecessary end-of-life treatments and frequent transfers from nursing homes to hospitals to expire.

Unfortunately, each of these benefits may not be realized because of any one or combination of barriers to hospice enrollment. Often there are barriers associated with family and resident knowledge deficits about hospice. These become evident when deep rooted cultural beliefs conflict with hospice philosophy such as a preference for lifesustaining treatments. Inability of staff to recognize and manage end-of-life symptoms, especially among residents with dementia hinder early hospice enrollment. Staffing shortages and high turnover in nursing homes can directly affect hospice enrollment, especially when attempting to keep staff trained on end-of-life care. Finally, reimbursement issues and cultural clashes may hinder enrollment. Organizational clashes exist between restorative nursing home guidelines and palliative hospice principles. 
Table 3-2 On-line End-of-life Educational Resources for Nurses

\begin{tabular}{|c|c|c|}
\hline Resource & Description & Source for On-line Information \\
\hline ELNEC & $\begin{array}{l}\text { End-of-Life Nursing Education } \\
\text { Consortium offers a series of } \\
\text { modules designed to "train the } \\
\text { trainer" about end-of-life } \\
\text { issues }\end{array}$ & www.aacn.nche.edu/elnec/ \\
\hline PERT & $\begin{array}{l}\text { Palliative Care Educational } \\
\text { Resource Team provides } \\
\text { education to licensed and } \\
\text { unlicensed staff, including } \\
\text { decision-making skills and } \\
\text { end-of-life care for residents } \\
\text { with dementia }\end{array}$ & www.swedishmedical.org/PERT.htm \\
\hline TNEEL & $\begin{array}{l}\text { Toolkit for Nurturing } \\
\text { Excellence at End-of-Life } \\
\text { Transition Program is based on } \\
\text { the American Association of } \\
\text { Colleges of Nursing's } \\
\text { competencies in palliative } \\
\text { education }\end{array}$ & www.tneel.uic.edu \\
\hline HPNA & $\begin{array}{l}\text { The Hospice and Palliative } \\
\text { Nurses Association provides a } \\
\text { wealth of information, } \\
\text { including position statements } \\
\text { and assistance with standards } \\
\text { of care }\end{array}$ & www.hpna.org \\
\hline Wisconsin & $\begin{array}{l}\text { Palliative Care Program at the } \\
\text { Medical College of Wisconsin }\end{array}$ & www.mcw.edu/pallmed \\
\hline Rhode Island & $\begin{array}{l}\text { Rhode Island Partnership to } \\
\text { Improve End-of-Life care: } \\
\text { "Train the Trainer" educational } \\
\text { curriculum and "Continuous } \\
\text { Quality Improvement Project } \\
\text { in Pain Management" }\end{array}$ & www.chcr.brown.edu/commstate \\
\hline
\end{tabular}




\section{IMPLICATIONS}

Much of the literature on increasing hospice enrollment in nursing homes is focused on educational interventions. Many of the barriers identified warrant further investigation beyond educational initiatives. Exploring cultural backgrounds or speaking with a pastor may be the catalyst to hospice enrollment. Likewise, exploring potential areas of liability for hospice in nursing homes are needed. In addition, many authors seem to focus on the idea of hospice in the "home" setting and while the nursing home does become a residents "home", hospice brings different concerns into this setting.

Conflicts between nursing home and hospice staff may require a proactive administrative lead. Techniques that increase individual empowerment could reduce this friction. This means asking nursing home nurses to help determine which residents may be hospice eligible and then reinforcing how hospice benefits the resident first, but may inadvertently offer the nurse much needed assistance with care. Administrators who invite hospices to bring "open houses" into the facility see the benefits of breaking down these traditional organizational barriers creating a "win-win" situation for everyone. However, careful consideration for hospice and nursing home policy and procedure are needed. Administrators and staff who understand the rules and regulations of hospice and long-term-care are better prepared to work together. This means that the continuity of care receives less interruptions and the risk for liability is decreased.

More system-wide barriers may require stakeholders creating key policy initiatives at the state and federal level. The MDS 3.0 will be available in 2009 and many of the concerns related to lack of palliative care might be better addressed. Initiatives creating transparent and sound reimbursement options between hospice and nursing homes should be at the forefront of policy development. Nursing homes may continue to seek higher paid interventions until equal reimbursement occurs for hospice, palliative, and restorative care.

Identifying individuals who are terminal and expected to live less than 6 months has been identified as a barrier to enrollment. This practice is the result of the Medicare Hospice Benefit (MHB) requiring a physician to certify that a resident has less than 6 months to live. However, this should not be a significant barrier to enrollment. Residents who meet recommended guidelines should be offered hospice services. Furthermore, residents can be recertified for an indefinite number of recertification periods. A resident and family can benefit from hospice for well more than 6 months. An educated family in conjunction with a prudent physician and nurse practitioner can be a strong force for initiating hospice services.

In conclusion, hospice has been helping individuals in the transition from life to death with as little pain and discomfort as possible for nearly 30 years, but currently more nursing home residents could be receiving the benefits of hospice than is now the case. Nurses and healthcare professionals working in long-term facilities should be encouraged to make a commitment to overcoming the barriers identified here to help increase hospice enrollment and provide the best possible care for residents approaching the end of life. Participating in on-line courses combined with on the job training is a first and important 
step to better prepare nursing home staff to manage terminal residents. However, much more needs to be done at the system level through state and federal policy change. 


\section{CHAPTER 4. METHODS}

\section{PURPOSE}

The purpose of this study was to identify the differences in pain medication administration between two different groups of deceased subjects, nursing home residents with malignant cancer and dementia with and without hospice services.

\section{DESIGN AND SETTING}

This study was a retrospective study of pain medication administration in nursing home residents who died with cancer and dementia and who received hospice services compared to residents who did not receive hospice services. The last 14 days of life were examined for this study.

Nursing homes throughout western Tennessee were recruited. Ten nursing homes agreed to participate. One nursing home yielded no subjects leaving a final sample consisting of nine nursing homes, seven non-profit and two for-profit.

This cross-sectional study explored the frequency, types, and amounts of pain medication administered, while simultaneously a case-control design examined the differences between a group of residents with hospice services and a group of residents without hospice services for the relationships among pain, cancer, and dementia.

\section{SPECIFIC AIMS AND HYPOTHESES}

The primary aims of this study were (1) to determine the differences in administered pain medications for cognitively impaired residents who died from cancer while receiving hospice services as compared with those not receiving hospice services and (2) to determine if discomfort related pain behaviors among nursing home residents with cancer and dementia decrease with increasing cognitive impairment.

\section{Specific Aim One}

Specific Aim One was to determine the differences in administered pain medications for cognitively impaired residents who died from cancer while receiving hospice services as compared with those not receiving hospice services. The following eight hypotheses were associated with this aim.

- Hypothesis 1. Residents who received hospice services would receive more scheduled narcotic analgesic than residents who did not receive hospice services. 
- Hypothesis 2. Residents who received hospice services would receive greater total equivalent dose units (EDU's) of narcotic analgesic than residents who did not receive hospice services.

- Hypothesis 3. Residents who received hospice services would receive greater total dose number of non-narcotic analgesics (TDNN) than residents who did not receive hospice services.

- Hypothesis 4. Residents who received hospice services would receive more PRN narcotic analgesic than residents who did not receive hospice services.

- Hypothesis 5. Residents who received hospice services would receive more scheduled non-narcotic analgesic than residents who did not receive hospice services.

- Hypothesis 6. Residents who received hospice services would receive more PRN non-narcotic analgesic than residents who did not receive hospice services.

- Hypothesis 7. Residents who received hospice services would have different cognitive performance scores (CPS) than residents who did not receive hospice services.

- Hypothesis 8. Residents who received hospice services would receive greater total dose numbers of drug potentiators (TDNP) than would residents who did not receive hospice services.

\section{Specific Aim Two}

Specific Aim two was to determine if discomfort related pain behaviors among nursing home residents with cancer and dementia decrease with increasing cognitive impairment. The following hypothesis is associated with this aim.

Hypothesis 9. Discomfort related pain behaviors among all residents will be decreased with increasing cognitive impairment.

\section{HUMAN SUBJECTS CONSIDERATION}

Approval was obtained from the University of Tennessee Health Science Center Review Board for the dates needed for data collection. Clarification and revision required by the IRB was done. The study was approved and given exempt status (Appendix A) and a revision for recruitment was approved (Appendix B). 


\section{METHODS}

The sample was drawn from nursing home residents with malignant cancer and dementia in nine nursing homes in western Tennessee. The facilities were a mix of for profit $(n=7)$ and nonprofit $(n=2)$ with a size range of 68 to 180 beds.

Inclusion criteria were residents who resided and died in a nursing home between January 1, 2003 and July 1, 2009 with malignant cancer and dementia. Initial subject recruitment began by using Vista KEANE MDS ${ }^{\circ}$ software in each nursing home (Keane Care Inc. Redmond WA). Prospective subjects were located using the following methodology: First, 10 malignant cancer codes were used to search "client by diagnosis". "Client by diagnosis" is a default option in the software used to locate nursing home residents with specific traits. The cancer diagnoses as described in chapter 5 were obtained from the Centers for Disease Control (CDC) top 10 cancers of the overall population for all races and genders in 2004 (Centers for Disease Control, 2007). No subjects were located who had non-Hodgkin's lymphoma but the other nine are represented in the sample.

Second, each medical record was retrieved to determine a positive diagnosis of Alzheimer's disease, Lewy body dementia, vascular dementia, or mixed. Third, a CPS score was calculated from their admission MDS. The CPS was calculated from the first MDS because CPS scores may decline over time but were not likely to improve. The CPS is calculated using a specific algorithm and scoring grid using specific MDS items. Fourth, a DBS score was calculated from the most recent MDS before death realizing the most recent MDS may have been in the previous 90 days. Lastly, a diagnosis of malignant cancer and cause of death were confirmed in the medical record. This methodology was thought to be the best way to capture active cancer pain among individuals with dementia in a retrospective study.

Exclusion criteria were inability to determine the cause of death, and incomplete or missing medical records. A total of 55 subjects meeting eligibility were located and met inclusion criteria.

\section{Pain Medication Administration}

A Medical Chart Review Form (MCRF) was created for data collection (Appendix C). The primary diagnosis was noted. Opioid containing medications were documented, both scheduled and PRN doses and amounts were recorded over the last 14 days of life. Non-analgesic medications (potentiators) were documented and counted over the last 14 days of life. The dose amount for narcotic medications was entered into the MCRF form. Opioids were converted to equivalent dose units (EDU's) for analysis using the formula specified by the Equianalgesic Opioid Conversion rations for Patients Previously Receiving Other Opioids (Arkansas Medicaid) on-line calculator (Arkansas Medicaid, 2007). This calculator provides an EDU conversion factor for converting narcotic dosages to EDU's. For example, a resident received 30 total $\mathrm{mg}$ of Morphine, 40 $\mathrm{mg}$ of Hydrocodone, and $125 \mathrm{mcg}$ of Fentanyl over the last two weeks of life. Each of 
these has an EDU equivalency. Thirty mg of Morphine equals 1.13 EDU's, $40 \mathrm{mg}$ of hydrocodone equals 1.33 EDU's, and $125 \mathrm{mcg}$ of Fentanyl equals 15.0 EDU's for a total of 17.43 EDU's during the last two weeks of life.

\section{Demographics/Sample Characteristics}

Demographic information included age, gender, type of cancer, facility, and ethnicity (African-American, Caucasian). The hospice group was compared to the nonhospice group for equivalency using the Spearman's Rank Correlation procedure and the Mann Whitney $U$ statistic.

The primary aims of this study were (1) to determine the differences in administered pain medications for cognitively impaired residents who died from cancer while receiving hospice services as compared with those not receiving hospice services and (2) to determine if discomfort related pain behaviors among nursing home residents with cancer and dementia decrease with increasing cognitive impairment.

\section{Specific Aim One}

Specific Aim One was to determine the differences in administered pain medications for cognitively impaired residents who died from cancer while receiving hospice services as compared with those not receiving hospice services. The following eight hypotheses were associated with this aim.

- Hypothesis 1. Residents who received hospice services would receive more scheduled narcotic analgesic than residents who did not receive hospice services.

- Hypothesis 2. Residents who received hospice services would receive greater total equivalent dose units (EDU's) of narcotic analgesic than residents who did not receive hospice services.

- Hypothesis 3. Residents who received hospice services would receive greater total dose number of non-narcotic analgesics (TDNN) than residents who did not receive hospice services.

- Hypothesis 4. Residents who received hospice services would receive more PRN narcotic analgesic than residents who did not receive hospice services.

- Hypothesis 5. Residents who received hospice services would receive more scheduled non-narcotic analgesic than residents who did not receive hospice services. 
- Hypothesis 6. Residents who received hospice services would receive more PRN non-narcotic analgesic than residents who did not receive hospice services.

- Hypothesis 7. Residents who received hospice services would have different cognitive performance scores (CPS) than residents who did not receive hospice services.

- Hypothesis 8. Residents who received hospice services would receive greater total dose numbers of drug potentiators (TDNP) than would residents who did not receive hospice services.

\section{Specific Aim Two}

Specific Aim Two was to determine if discomfort related pain behaviors among nursing home residents with cancer and dementia decrease with increasing cognitive impairment. The following hypothesis is associated with this aim.

Hypothesis 9. Discomfort related pain behaviors among all residents will be decreased with increasing cognitive impairment.

\section{Testing the Hypotheses}

In order to test the hypotheses, data were collected in the following manner:

- All scheduled opioids and dose given were entered into the MCRF, if no opioid was administered then a " 0 " was entered for that day.

- All PRN opioids and dose given were entered into the data collection, if no PRN opioid was administered then a "0" was entered for that day.

- All scheduled non-narcotic analgesics types and dose given were entered into the MCRF, if no non-narcotic analgesic was administered then a "0" was entered for that day.

- All PRN non-narcotic analgesic types and dose given were entered into the MCRF; if no non-narcotic analgesic was administered then a " 0 " was entered for that day.

- All scheduled potentiators, types and dose given were entered into the MCRF, if none were administered then a " 0 " was entered for that day.

- All PRN potentiators, types and dose given were entered into the MCRF; if none were administered then a " 0 " was entered into the form. 
- CPS and DBS scores were calculated on each subject using the established scoring grid for each instrument.

Mann Whitney U procedures were conducted on Hospice / Non Hospice and continuous variables. Bivariate correlations were conducted and reported on hospice enrollment and DBS scores. The Kruskal-Wallis procedure was conducted to answer the final hypothesis. Alpha was set at 0.05 . Beta was set at 0.20 (power of 80 ). 


\section{CHAPTER 5. RESULTS}

\section{SAMPLE CHARACTERISTICS AND DEMOGRAPHIC DATA}

Sociodemographic characteristics are located in Table 5-1. Forty-five percent were male, 29\% were African American, and 45\% were enrolled in hospice. The mean age of the sample was 86 (SD 7.84). Hospice enrollees are further described in Table 5-2. Frequency and percentages of cancer types are listed in Table 5-3. Greater than $50 \%$ of decedents had either colon/rectal or breast cancer.

Table 5-4 shows the results of hospice enrollment correlated with categorical demographic and pain variables. Gender and race were included in the table for completeness.

Table 5-5 shows the results of The Mann Whitney $U$ Statistic between hospice enrollment and continuous study variables. Age was included in the analysis for completeness.

Hypothesis 1 was, "Residents who received hospice services would receive more scheduled narcotic analgesic than residents who did not receive hospice services." This hypothesis was tested using The Spearman's correlation procedure (Table 5-4) and an Odds Ratio. This hypothesis was accepted. There is a significantly greater likelihood of being prescribed a scheduled narcotic analgesic (OR 5.5; 95\% CI 1.8 - 18.8) when enrolled in hospice.

Hypothesis 2 was, "Residents who received hospice services will have different pain management measured by greater total EDU's during the last two weeks of life? This hypothesis was tested using the Mann Whitney $U$ statistic. The results are found in Table 5 with descriptive statistics in Table 5-6. This hypothesis was accepted. Total EDU's were significantly greater among hospice enrollees $(U 226.5, p<.05)$.

Hypothesis 3 was, "Residents who received hospice services will have different pain management evidenced through receiving more TDNN during the last two weeks of life?" This hypothesis was tested using the Mann Whitney $U$ statistic (Table 5-5). This hypothesis was rejected.

Hypothesis 4 was, "Residents who received hospice services will have different pain management evidenced through being prescribed more of PRN narcotics?" This hypothesis was tested using the Spearman's correlation procedure (Table 5-4) and an Odds Ratio. This hypothesis was accepted. There is a significantly greater likelihood of being prescribed a PRN narcotic analgesic (OR 3.6; 95\% CI 1.2-11.3) when enrolled in hospice. However, individuals with higher cognitive levels were more likely (OR 3.67; 95\% CI 1.19-11.26) to be prescribed a PRN narcotic. Lower cognitive levels were defined as individuals with a CPS score of 4,5 , or 6 compared to higher cognitive levels with a CPS score of 1,2 , and 3 . 
Table 5-1 Sociodemographics of Study Sample $(\mathrm{N}=55)$

\begin{tabular}{lc}
\hline Characteristic & $\mathrm{n}(\%)$ \\
\hline Gender & \\
Male & $25(45)$ \\
Female & $30(54)$ \\
Race / Ethnicity & \\
White & $39(71)$ \\
Black & $16(29)$ \\
\hline
\end{tabular}

Mean Age (Standard Deviation): Hospice patients, 86 (8.81); Non-hospice patients 88 (6.71)

Table 5-2 Characteristics of Hospice Decedents $(\mathrm{N}=25)$

\begin{tabular}{lc}
\hline Characteristic & $\mathrm{n}(\%)$ \\
\hline Hospice patients & $25(45)$ \\
Gender & $11(20)$ \\
Male hospice patients & $14(25)$ \\
Female hospice patients & \\
Race / Ethnicity & $16(29)$ \\
White hospice patients & $6(11)$ \\
Black hospice patients
\end{tabular}

$\mathrm{N}=$ total number of hospice decedents; $\mathrm{n}=$ number in each characteristic subgroup

Table 5-3 Frequency and Percentage of Cancer Types $(\mathrm{N}=55)$

\begin{tabular}{lr}
\hline Cancer Type & $\mathrm{n}(\%)$ \\
\hline Colon / Rectal & $15(27.3)$ \\
Female breast & $14(25.5)$ \\
Prostate & $9(16.4)$ \\
Lung/Bronchiole & $6(10.9)$ \\
Uterine & $3(5.5)$ \\
Melanoma of skin & $2(3.6)$ \\
Ovarian & $2(3.6)$ \\
Kidney/Renal & $2(3.6)$ \\
Bladder & $1(1.8)$ \\
\hline
\end{tabular}

$\mathrm{N}=$ total number of hospice decedents; $\mathrm{n}=$ number in each characteristic subgroup 
Table 5-4 Correlations with Hospice Enrollment

\begin{tabular}{lcccccc}
\hline & & & & & Scheduled & PRN \\
& Gender & Race & $\begin{array}{c}\text { Scheduled } \\
\text { Narcotics }\end{array}$ & $\begin{array}{c}\text { PRN } \\
\text { Narcotics }\end{array}$ & $\begin{array}{c}\text { Non- } \\
\text { narcotics }\end{array}$ & $\begin{array}{c}\text { Norcotics } \\
\text { narcon }\end{array}$ \\
\hline Spearman's - rho & -.027 & -.102 & .393 & .312 & .257 & .137 \\
Sig (1-tailed) & .423 & .229 & $.001^{*}$ & $.010 \dagger$ & .137 & .160 \\
\hline
\end{tabular}

$* p<.01 ; \dagger p<.05$

$\mathrm{PRN}=$ as the situation demands

Table 5-5 Hospice Enrollment and Continuous Study Variables

\begin{tabular}{lccccc}
\hline & Age & TDNN $^{*}$ & TDNP $\dagger$ & CPS $\$$ & EDU§ \\
\hline Mann Whitney $U$ & 321.5 & 339.0 & 292.5 & 183.5 & 226.5 \\
$Z$ & -.671 & -.437 & -1.217 & -3.122 & -2.533 \\
Asymp. Sig (1-tailed) & .251 & .331 & .112 & $.001^{1}$ & $.005^{1}$ \\
\hline
\end{tabular}

${ }^{1} p<.01$

TDNN $=$ total dose number of narcotics; TDNP $=$ total dose number of potentiators;

$\mathrm{CPS}=$ cognitive performance scale; EDU = Equianalgesic dose units (of opioid)

*TDNN were calculated by counting all dose number of narcotic during the last 2 weeks of life.

$\dagger$ TDNP were calculated by counting all dose number of potentiators; i.e., benzodiazipines, sedatives, hypnotics, during the last 2 weeks of life.

$\$$ CPS scores were calculated from the admission Minimum Data Set using the instrument algorithm.

$\S E D U$ 's were calculated over the last 2 weeks of life and placed directly into the on-line calculator and converted to EDU amounts.

Table 5-6 Descriptive Sample Statistic of Hospice Enrollment and Mean Rank EDU

\begin{tabular}{lccc}
\hline Hospice & $\mathrm{n}$ & Mean Rank EDUs & Sum of Ranks \\
\hline Yes & 25 & 33.94 & 848.50 \\
No & 30 & $23.05^{1}$ & 691.50 \\
\hline
\end{tabular}

$\mathrm{n}=$ number in each group; EDU $=$ Equianalgesic dose units (of opioid)

${ }^{1} p<.01$ ( 1 tailed) 
Hypothesis 5 was, "Residents who received hospice services will have different pain management evidenced by being prescribed more scheduled non-narcotic analgesic?" This hypothesis was tested using The Mann Whitney $U$ statistic (Table 5-5). This hypothesis was rejected.

Hypothesis 6 was, "Residents who received hospice services will have different pain management evidenced by being prescribed more an as needed (PRN) non-narcotic analgesic?" This hypothesis was tested using The Mann Whitney $U$ statistic (Table 5-5). This hypothesis was rejected.

Hypothesis 7 was, "There are no differences between cognitive abilities between residents who received hospice services and those who did not. This hypothesis was tested using The Mann-Whitney U Statistic (Table 5-5). This hypothesis was rejected. Descriptive statistics for this hypothesis are found in Table 6. Hospice enrollment decreased as cognitive impairment increased $(U 220.0, p<.01)$ with no individuals with a CPS score of 6 (very severe impairment) enrolled in hospice. Descriptive statistics for this hypothesis are found in Table 5-7.

Hypothesis 8 was, "Residents who received hospice services will have different pain management evidenced by receiving more TDNP during the last two weeks of life?" This hypothesis was tested using the Mann Whitney $U$ Statistic (Table 5-5). This hypothesis was rejected.

Hypothesis 9 was, "Discomfort related pain behaviors among all residents will be decreased with increasing cognitive impairment." This hypothesis was accepted. Decedents with lower cognitive levels were more likely (OR 4.9; 95\% CI 1.6-15.6) to have a DBS score of zero. Lower cognitive levels were defined as individuals with a CPS score of 4, 5, or 6 compared to higher cognitive levels with a CPS score of 1, 2, and 3. Descriptive statistics for this hypothesis are found in Table 5-8.

An expert in pain, Perry Fine (personal communication, September, 21, 2009) was asked to rate the cancer types as those likely to be painful to further explore the phenomenon that no person with very severe cognitive impairment was enrolled in hospice and that $40 \%$ of the subjects did not receive any narcotic analgesic at the end of life and of these $31 \%$ were not enrolled in hospice while $9 \%$ were This resulted in a dichotomous variable of cancer with "predictably painful" tumors that metastasize to the bone (breast, lung, prostate, and renal) and those that do not (colon/rectal, bladder, melanoma of the skin, ovarian, and uterine). Using Crosstabs in SPSS 16.0, this analysis resulted in 9 individuals with predictably painful metastatic cancer who were very severely cognitively impaired receiving no narcotic analgesic during the last two weeks of life. Of note is that 29 of the 42 subjects $(70 \%)$ who did not receive any narcotic analgesic at the end of life had predictably painful metastatic cancer.

In summary, this study enrolled approximately $50 \%$ of each gender. One out of every three individuals was African American and the average age was 87. Nearly half of the individuals were enrolled in hospice and $50 \%$ of all subjects had breast or colon/rectal 
Table 5-7 Descriptive Sample Statistics of CPS Groups

\begin{tabular}{ccc}
\hline CPS* score & N (hospice $=\mathrm{n})$ & Mean EDU's (SD) \\
\hline 1 & $7(4)$ & $10.13(11.14)$ \\
2 & $7(5)$ & $21.83(12.40)$ \\
3 & $11(8)$ & $12.08(12.40)$ \\
4 & $10(2)$ & $10.77(17.05)$ \\
5 & $8(5)$ & $2.36(6.13)$ \\
6 & $12(0) \dagger$ & $4.0(7.45)$ \\
\hline
\end{tabular}

$\mathrm{N}=$ total number in each CPS subgroup, $\mathrm{n}=$ total number of hospice enrollees in each subgroup

${ }^{*}$ CPS is scored from $1=$ borderline cognitively intact to $6=$ very severely cognitively impaired.

$\uparrow$ No individual with a CPS score of 6 was enrolled in hospice.

Table 5-8 CPS and DBS Group Comparisons

\begin{tabular}{lc}
\hline CPS & Mean DBS (SD) \\
\hline $1(\mathrm{n}=7)$ & $4.43(5.02)$ \\
$2(\mathrm{n}=7)$ & $4.43(7.34)$ \\
$3(\mathrm{n}=11)$ & $9.09(7.46)$ \\
$4(\mathrm{n}=10)$ & $7.70(16.31)$ \\
$5(\mathrm{n}=8)$ & $6.12(11.52)$ \\
$6(\mathrm{n}=12)$ & $1.92(3.59)^{*}$ \\
\hline $\mathrm{N}=$ total number in each CPS group, SD = standard deviation
\end{tabular}

*Decedents with lower cognitive levels $(4,5,6$ vs. $1,2,3)$ were more likely [OR $4.9 ; 95 \%$ CI 1.6-15.6] to have a DBS score of zero. 
cancer. The group sizes and data distribution were appropriate for nonparametric procedures. The Spearman's correlations and Odds ratios showed strong correlations between hospice enrollees and being prescribed a scheduled narcotic and higher cognitive levels and being prescribed a PRN narcotic. The Mann-Whitney $U$ Statistic showed a significant relationship between hospice enrollees, CPS score and total EDU's indicating that as cognitive impairment increases both hospice enrollment and total dose of opioid analgesic decrease. No individual with very severe cognitive impairment was enrolled in hospice services.

\section{DISCUSSION}

This study adds to and extends the current literature on pain management in the nursing home. This study shows that untreated pain continues to be a serious problem among nursing home residents with dementia. The literature is extended by showing that nearly half of the subjects enrolled received no narcotic pain medication in the presence of likely painful bone metastasis.

These findings also suggest that very severely cognitively impaired individuals are not enrolled in hospice. None of the subjects with a CPS score of 6 were enrolled in hospice. The relationship between hospice enrollment and CPS scores is telling. CPS scores of 4, 5, and 6 have been shown to correlate with an MMSE score of $<10$ and CPS scores of 5 and 6 correlate with an MMSE score of $<5$ (Hartmaier, et al., 1995; Morris, et al., 1994) (Morris, Fries, Mehr, et al 1994; Hartmaier, Sloane, Guess, Koch, Mitchell, Phillips, 1995) (Hartmaier, et al., 1995; Morris, et al., 1994). This suggests that the most severely cognitively impaired are not being enrolled in hospice and that current methods used to determine hospice enrollment among persons with malignant cancer and very severe cognitive impairment do not work among nursing homes in western Tennessee. A secondary reason for decreased hospice enrollment appears to be blunted pain related behaviors. Individuals with CPS scores of 6 had the lowest DBS scores and this study showed that DBS scores significantly decrease with increasing cognitive impairment. Hospice enrollment might have increased the use of narcotic analgesia at the end of live for these residents.

Nursing home residents enrolled in hospice were more likely to be prescribed a narcotic and thus received larger quantity of narcotic analgesic during the last two weeks of life. Introducing this paradigm into practice among nurse practitioners and physicians who provide primary care could help reduce the amount of untreated pain in the nursing home. This means that prescribing scheduled medications (narcotic or non-narcotic) for various painful co-morbidities appears to be one way to reduce the possibility of being untreated for pain. Among the severely cognitively impaired whose pain behaviors become blunted, scheduled medications appear to be the best way to manage their pain.

Male and female participants were nearly equally represented in the study. Also the ratio of White to Black enrollees was similar to the United States national average with Black enrollees representing nearly $30 \%$ of this sample. Hospice enrollees were

slightly younger than non-hospice enrollees. However, bivariate analysis of nursing home 
characteristics showed that race was significantly correlated with facility $(-.301, p=.025)$ and that hospice was significantly correlated with facility $(.337, p=.012)$. These findings suggest that educational efforts to decrease administrative bias that may prohibit hospice enrollment may not be working in Western Tennessee. Methods to enroll hospice patients based on behavioral cues apparently do not work in the very severely cognitively impaired.

Pain related discomfort behaviors were found to significantly decrease as cognitive impairment increases. Bivariate analysis of discomfort behaviors showed that race was correlated with DBS scores. Black Americans had significantly higher DBS scores. However, as previously mentioned, this difference could be attributed to facility bias or it may be contributed to the actual genetic, socio-cultural, or ethnic differences. Another reason for this finding could be rater bias when filling out the MDS data instrument. Further analysis of this finding showed that the mean total EDU's were nearly identical between Black and White residents. This finding has important implications for pain behavior instrument development. Current instruments rarely, if at all, make cultural, ethnic, or racial adjustments. Do Black individuals demonstrate significantly more pain related behaviors that White individuals? Did Black and White older adults in this study receive identical pain relief or were older Black adults undertreated for pain?

A second significant correlation with DBS scores was cancer type. The four highest DBS scores in the study were associated with prostate and breast cancer. These cancers were identified to have predictably painful metastasis to the bone.

\section{RECOMMENDATIONS}

This study demonstrated that $40 \%$ of individuals with malignant cancer and dementia were under medicated at the end-of life. Individuals with very severe cognitive impairment are more likely to be undertreated for pain and not enrolled in hospice services.

Currently there is no valid and reliable way to assess pain among persons with very severe cognitive impairment. This study further demonstrated that total amount of pain medication decreased as cognitive impairment increased. This means that self-report remains the most valid assessment tool nurses use and when self-report and behaviors becomes blunted nursing home residents with malignant cancer and dementia are undertreated for pain. The author recommends that new methods be developed for assessment of pain among individuals with very severe dementia.

\section{FUTURE RESEARCH}

Future studies using individuals with cognitive impairments will require more research to discern if the pain pathways are intact. Pain consists of emotional and sensory dimensions. Determining how pain affects persons who have the ability to communicate 
is well established in the literature - it is whatever the person says it is. However, as the individual looses the ability to communicate assessment has been difficult and current models rely on behavioral assessment and this will not work in the severely cognitively impaired

Findings from this dissertation will provide direction for future research and the next step is to determine the feasibility of using functional magnetic resonance imaging (fMRI) to elucidate the pain pathways among persons with very severe Dementia of the Alzheimer's Type (DAT). Current literature suggests that individuals with DAT have pain, but may not be able to express it. Researchers, using fMRI among cognitively intact individuals have been able to discern between lateral and medial pain pathways demonstrating sensory and emotional pain perception. This means that very severely cognitively impaired older adults (CIOA) may be able to feel the pain but be unable to verbalize or express it through physical behaviors. We must discern if the pain pathways are intact among the very severely cognitively impaired, and if they are, we must change the way we currently manage their pain and provide nursing care.

A second area of future research is to determine how the decision is made to enroll in hospice. Methods exist to help clinicians determine eligibility for hospice enrollment among persons with dementia, however findings from this study show that people with severe dementia are not being enrolled. More research is needed to better understand just why this is occurring.

\section{POLICY IMPLICATIONS}

Medicaid is the major payer for long term care and Medicare is the major payer for hospice services in the nursing home. Investigators have explained how hospice enrollment can save millions of dollars to the Medicare system, yet enrollment continues to be a problem. Reimbursement for services, ethical incentives for enrollment, and equal reimbursement to nursing homes for hospice are policies that must be implemented in order to increase enrollment.

Individuals with dementia and painful co-morbidities should be given pain medications until the time that scientists discern if the pain pathways in dementia are or are not intact. A policy change under Medicare would be required to effectively regulate pain management in persons who cannot behave or speak. This means that institutions and care providers would not be federally reimbursed unless these individuals receive some type of documented pain medication administration.

New quality measures / indicators in the nursing home or hospital should include pain medication administration among residents / patients with dementia. For example, admission protocols could be used that provide an easy algorithm for providers to follow when an individual is admitted with dementia. Providing choices of scheduled nonnarcotic and narcotic medications with a PRN option then becomes the standard of care for individuals who cannot speak or behave normally in pain. A second quality measure could be testing the efficacy of the pain medication interventions. This means that 
individuals with dementia could have their urine and or hair randomly tested to determine if the prescribed medications are present. This intervention could be part of the state or federal survey and if medications are not present a system of accountability can begin. Currently, there is no program in place to administer or monitor the efficacy of medication interventions among individuals with severe dementia.

\section{MOVING FINDINGS INTO PRACTICE}

Moving these dissertation findings into practice will require additional research on the physiology of dementia and pain in persons with severe dementia. A proposed next study will use fMRI to elucidate the pain pathways in persons with severe dementia. This technology will hopefully provide evidence that one of not all of the pain pathways is intact. This science can then be used to design intervention and outcome studies for the very severely cognitively impaired. 


\section{LIST OF REFERENCES}

Algase, D. L. (2006). What's so critical about evidence-based nursing practice? Research \& Theory for Nursing Practice, 20(2), 99-100.

Alzheimer's Association (2008). What is Alzheimer's. Retrieved November 27, 2008, from http://www.alz.org/alzheimers disease what is alzheimers.asp?type=homepagef $\underline{\text { lash }}$

Alzheimer's Association (2009). Alzheimer's disease facts and figures. Retrieved October 17,2009 , from http://www.alz.org/national/documents/report_alzfactsfigures2009.pdf

Alzheimer's Society (2008). What is vascular dementia. Retrieved November 11, 2007, from http://alzheimers.org.uk/site/scripts/documents_info.php?categoryID=200137\&do cumentID=161\&pageNumber $=1$

Arkansas Medicaid (2007). Opioid dosing conversion calculator.xls. Retrieved November 11, 2007, from http://webcache.googleusercontent.com/search?q=cache:x5UL8AZAkQoJ:https:// www.medicaid.state.ar.us/Download/provider/pharm/OpioidDosingConversionCa lculator.xls + OpioidDosingConversionCalculator $x \mathrm{xls} \& \mathrm{~cd}=1 \& \mathrm{hl}=\mathrm{en} \& \mathrm{ct}=\mathrm{clnk} \& \mathrm{gl}=$ us\&client=firefox-a

Barrie, M. A. (2002). Objective screening tools to assess cognitive impairment and depression. Topics in Geriatric Rehabilitation, 18(2), 28-46.

Beatty, G. E. (2006). Shedding light on Alzheimer's. Nurse Practitioner, 31(9), 32.

Beck, C., Frank, L., Chumbler, N. R., O'Sullivan, P., Vogelpohl, T. S., Rasin, J., et al. (1998). Correlates of disruptive behavior in severely cognitively impaired nursing home residents. Gerontologist, 38(2), 189-198.

Benedetti, F., Vighetti, S., Ricco, C., Lagna, E., Bergamasco, B., Pinessi, L., et al. (1999). Pain threshold and tolerance in Alzheimer's disease. Pain, 80(1-2), 377-382.

Bernabei, R., Gambassi, G., Lapane, K., Landi, F., Gatsonis, C., Dunlop, R., et al. (1998). Management of pain in elderly patients with cancer JAMA, 279(23), 1877-1882.

Bingel, U., Quante, M., Knab, R., Bromm, B., Weiller, C., \& Buchel, C. (2002). Subcortical structures involved in pain processing: evidence from single-trial fMRI. Pain, 99(1-2), 313-321.

Bjoro, K., \& Herr, K. A. (2008). Assessment of pain in the nonverbal or cognitively impaired older adult. Clinics in Geriatric Medicine, 24(2), 237-262. 
Bornhovd, K., Quante, M., Glauche, V., Bromm, B., Weiller, C., \& Buchel, C. (2002). Painful stimuli evoke different stimulus-response functions in the amygdala, prefrontal, insula and somatosensory cortex: a single-trial fMRI study. Brain, 125(Pt 6), 1326-1336.

Braun, K. L., \& Zir, A. (2005). Using an interactive approach to teach nursing home workers about end-of-life care. Journal of Hospice \& Palliative Nursing, 7(5), 280-288.

Buchanan, R. J., Choi, M., Wang, S., \& Ju, H. (2004). End-of-life care in nursing homes: Residents in hospice compared to other end-stage residents. Journal of Palliative Medicine, 7(2), 221-232.

Carr, D. B., Duchek, J. M., Meuser, T. M., \& Morris, J. C. (2006). Older adult drivers with cognitive impairment. American Family Physician, 73(6), 1029.

Casarett, D., Karlawish, J., Morales, K., Crowley, R., Mirsch, T., \& Asch, D. A. (2005). Improving the use of hospice services in nursing homes: A randomized controlled trial. JAMA: Journal of the American Medical Association, 294(2), 211-217.

Casarett, D., van Ness, P. H., O'Leary, J. R., \& Fried, T. R. (2006). Are patient preferences for life-sustaining treatment really a barrier to hospice enrollment for older adults with serious illness? Journal of the American Geriatrics Society, 54(3), 472-478.

Casarett, D. J., Crowley, R. L., \& Hirschman, K. B. (2004). How should clinicians describe hospice to patients and families? Journal of the American Geriatrics Society, 52(11), 1923-1928.

Centers for Disease Control (2007). United States cancer statistics: 1999-2006 incidence and mortality web-based report. Retrieved August 5, 2008, from http://apps.nccd.cdc.gov/uscs/toptencancers.aspx

Centers for Medicare and Medicaid (2008). The Medicare hospice benefit. Retrieved November 24, 2008, from http://www.medicare.gov/publications/Pubs/pdf/02154.pdf

Cherney, C. L. (2008). Determining hospice benefit for patients with dementia. JAMA, 299(15), 1774-1775.

Chopra, A., Cavalieri, T. A., \& Libon, D. J. (2007). Dementia screening tolls for the primary care physician. Clinical Geriatrics, 15(1), 38-45.

Chung, J. C. C. (2006). Care needs assessment of older Chinese individuals with dementia of Hong Kong. Aging \& Mental Health, 10(6), 631-637.

Clarkin, M. (2008). Nursing homes facing high turnover rates. Retrieved December 12, 2008, from http://www.hutchnews.com/Todaystop/nurse2008-12-13T21-00-27 
Cole, L. J., Farrell, M. J., Duff, E., Barber, J. B., Egan, G. F., \& Gibson, S. J. (2006). Pain sensitivity and fMRI pain-related brain activity in Alzheimer's disease. Brain: A Journal of Neurology, 129(Part 11), 2957-2965.

Connecticut Hospice (1998). 10 principles of hospice care. Cancer Therapeutics, 1(2), 11.

Cook, A. K., Niven, C. A., \& Downs, M. G. (1999). Assessing the pain of people with cognitive impairment. International Journal of Geriatric Psychiatry, 14(6), 421425.

Craig, A. (n.d.). Mapping pain in the brain. Retrieved October, 12, 2009, from http://www.wellcome.ac.uk/en/pain/microsite/science2.html\#

Davis, K. (2006). fMRI of clinical pain. In S. Faro \& F. Mohamed (Eds.), Functional MRI: Basic principles and clinical applications. New York: Springer.

Davis, M. P., \& Srivastava, M. (2003). Demographics, assessment and management of pain in the elderly. Drugs \& Aging, 20(1), 23-57.

Decker, S. A., \& Perry, A. G. (2003). The development and testing of the PATCOA to assess pain in confused older adults. Pain Management Nursing, 4(2), 77-86.

DeWaters, T., Popovich, J., \& Faut-Callahan, M. (2003). An evaluation of clinical tools to measure pain in older people with cognitive impairment. British Journal of Community Nursing, 8(5), 226-234.

Dobbs, D. J., Hanson, L., Zimmerman, S., Williams, C. S., \& Munn, J. (2006). Hospice attitudes among assisted living and nursing home administrators, and the LongTerm Care Hospice Attitudes Scale. Journal of Palliative Medicine, 9(6), 13881400 .

Duncan, J. G., Forbes-Thompson, S., \& Bott, M. J. (2008). Unmet symptom management needs of nursing home residents with cancer. Cancer Nursing, 31(4), 265-273.

Engle, V. F., Graney, M. J., \& Chan, A. (2001). Accuracy and bias of licensed practical nurse and nursing assistant ratings of nursing home residents' pain. Journals of Gerontology Series A-Biological Sciences \& Medical Sciences, 56(7), M405-411.

Ersek, M., \& Wilson, S. A. (2003). The challenges and opportunities in providing end-oflife care in nursing homes. Journal of Palliative Medicine, 6(1), 45-57.

Evans, B. D. (2002). Improving palliative care in the nursing home from a dementia perspective. Journal of Hospice \& Palliative Nursing, 4(2), 91-102.

Farrell, M. J., Katz, B., \& Helme, R. D. (1996). The impact of dementia on the pain experience. Pain, 67(1), 7-15. 
Feldt, K. S. (2000). The checklist of nonverbal pain indicators (CNPI). Pain Management Nursing, l(1), 13-21.

Feldt, K. S., Ryden, M. B., \& Miles, S. (1998). Treatment of pain in cognitively impaired compared with cognitively intact older patients with hip-fracture. Journal of the American Geriatric Society, 46, 1079-1085.

Ferrell, B. A., Ferrell, B. R., \& Osterweil, D. (1990). Pain in the nursing home. Journal of the American Geriatrics Society, 38(4), 409-414.

Ferrell, B. A., Ferrell, B. R., \& Rivera, L. (1995). Pain in cognitively impaired nursing home patients. Journal of Pain \& Symptom Management, 10(8), 591-598.

Ferrell, B. A., Stein, W. M., \& Beck, J. C. (2000). The geriatric pain measure: Validity, reliability and factor analysis. Journal of the American Geriatrics Society, 48(12), 1669-1673.

Folstein, M. F., Folsten, S.E., \& McHugh, P.R. (1975). Mini-mental state: A practical method for grading the cognitive state of patietns for the clinician. The Journal of Psychiatric Research, 12, 189-198.

Frampton, M. (2003). Experience assessment and management of pain in people with dementia. Age \& Ageing, 32(3), 248-251.

Freeman, K., Smyth, C., Dallam, L., \& Jackson, B. (2001). Pain measurement scales: A comparison of the Visual Analogue and Faces Rating Scales in measuring pressure ulcer pain. Journal of Wound, Ostomy \& Continence Nursing, 28(6), 290-296.

Gagliese, L. (2001). Assesment of pain in the elderly. In D. Turk \& R. Melzack (Eds.), Handbook of pain assessment. New York: Guilford Press.

Gatchel, R. J. (2004). Comorbidity of chronic pain and mental health disorders: The biopsychosocial perspective. American Psychologist(November), 795-805.

Geriatric Research Group (n.d.). Clinical definitions. Retrieved November 3, 2008, from http://www.fhs.mcmaster.ca/grg/definitions.htm

Gibson, S., Voukelatos, X., Ames, D., \& et al (2001). An examination of pain perception and cerebral event-related potentials follwoing carbon dioxide laser stimulation in patients with Alzheimer's disease and aged-matched control volunteers. Pain Research and Management, 6, 126-132.

Hadjistavropoulos, T., Craig, K., Martin, N., \& et al. (1997). Toward a research outcome measure of pain in frail elderly in chronic care. The Pain Clinic, 10, 71-79. 
Hanson, L., Eckert, J., Dobbs, D., Williams, C., Caprio, A., Sloane, P., et al. (2008). Symptom experience of dying long-term care residents. Journal of the American Geriatrics Society, 56(1), 91-98.

Hanson, L., Reynolds, K., Henderson, M., \& Pickard, G. (2005). A quality improvement intervention to increase palliative care in nursing homes. Journal of Palliative Medicine, 8(3), 576-584.

Hanson, L., Sengupta, S., \& Slubicki, M. (2005). Access to nursing home hospice: Perspectives on nursing home and hospice administrators. Journal of Palliative Medicine, 8(6), 1207-1213.

Happ, M. B. (2000). Interpretation of nonvocal behavior and the meaning of voicelessness in critical care. Social Science \& Medicine, 50(9), 1247-1255.

Hartmaier, S. L., Sloane, P. D., Guess, H. A., Koch, G. G., Mitchell, C. M., \& Phillips, C. D. (1995). Validation of the minimum data set cognitive performance scale: Agreement with the mini-mental state examination. Journal of Gerontology, 50, M128-m133.

Harvath, T. A. (1994). Interpretation and management of dementia-related behavior problems. Clinical Nursing Research, 3(1), 7-26.

Harvath, T. A., Beck, C., Flaherty-Robb, M., Hartz, C. H., Specht, J., Sullivan-Marx, E., et al. (2006). Best practice initiatives in geriatric nursing: Experiences from the John A. Hartford Foundation Centers of Geriatric Nursing Excellence. Nursing Outlook, 54(4), 212-218.

Hebert, L., Scherr, P., Bienias, J., Bennett, D., \& Evans, D. (2003). Alzheimer's disease in the US population: Prevalence estimates using the 2000 US census. Archives of Neurology, 60(8), 1119-1122.

Herr, K., Bursch, H., \& Black, B. (2008). Evaluation of Discomfort Behavior Scale (DBS). Retrieved November 12, 2008, from http://prc.coh.org/PainNOA/DBS D.pdf

Herr, K., Bursch, H., Miller, L., \& Swafford, K. (2010). Use of pain-behavioral assessment tools in the nursing home: Expert consensus recommendations for practice. Journal of Gerontological Nursing, 36(3), 19-29.

Herr, K. A., Bjoro, K., \& Decker, S. (2006). Tools for assessment of pain in nonverbal older adults with dementia: A state-of-the-science review. Journal of Pain \& Symptom Management, 31(2), 170-192.

Herr, K. A., \& Decker, S. (2004). Assessment of pain in older adults with severe cognitive impairment. Annals of Long Term Care, 12(4), 46-52. 
Herr, K. A., \& Garand, L. (2001). Assessment and measurement of pain in older adults. Clinics in Geriatric Medicine, 17(3), 457-478.

Herr, K. A., Mobily, P. R., Kouhout, F. J., \& Wagner, D. (1998). Evaluation of the faces pain scale for use with the elderly. The Clinical Journal of Pain, 14, 29-38.

Heye, M. L. (1997). Pain assessment in elders: Practical tips. Nurse Practitioner Forum, 8(4), 133-139.

Higginson, I. J., Finlay, I. G., Goodwin, D. M., Hood, K., Edwards, A. G. K., Cook, A., et al. (2003). Is there evidence that palliative care teams alter end-of-life experiences of patients and their caregivers? Journal of Pain \& Symptom Management, 25(2), 150-168.

Hoffman, D., \& Tarzain, A. (2005). Dying in America: An examination of policies that deter adequate end-of-life care in nursing homes. The Journal of Law, Medicine, and Ethics(summer), 294-309.

Horgas, A., \& Miller, L. (2008). Pain assessment in people with dementia. American Journal of Nursing, 108(7), 62-71.

Horgas, A. L., \& Dunn, K. (2001). Pain in nursing home residents. Comparison of residents' self-report and nursing assistants' perceptions. Incongruencies exist in resident and caregiver reports of pain; therefore, pain management education is needed to prevent suffering. Journal of Gerontological Nursing, 27(3), 44-53.

Horgas, A. L., \& Tsai, P. (1998). Analgesic drug prescription and use in cognitively impaired nursing home residents. Nursing Research, 47(4), 235-242.

Hutt, E., Pepper, G. A., Vojir, C., Fink, R., \& Jones, K. R. (2006). Assessing the appropriateness of pain medication prescribing practices in nursing homes. Journal of the American Geriatrics Society, 54(2), 231-239.

International Association for the Study of Pain (1979). Defining pain. Pain, 6, 250.

Jablonski, A., \& Wyatt, G. K. (2005). A model for identifying barriers to effective sympton management at the end of life. Journal of Hospice \& Palliative Nursing, 7(1), 23-36.

Johansson, E., Hamburg, K., Westman, G., \& Lindergren, G. (1999). An exploration of women's descriptions of symptoms. Social Science and Medicine, 48, 1791-1802.

Kamel, H. K., Phlavan, M., Malekgoudarzi, B., Gogel, P., \& Morley, J. E. (2001). Utilizing pain assessment scales increases the frequency of diagnosing pain among elderly nursing home residents. Journal of Pain \& Symptom Management, 21(6), 450-455. 
Kash, B. A., Castle, N. G., Naufal, G. S., \& Hawes, C. (2006). Effect of staff turnover on staffing: A closer look at registered nurses, licensed vocational nurses, and certified nursing assistants. Gerontologist, 46(5), 609-619.

Keene, P. R., \& Thompson, C. (2008). Educational implications of nurses' assessment and management of pain. Journal of Hospice \& Palliative Nursing, 10(6), 370375.

Killinger, L. Z., Morley, J. E., Kettner, N. W., \& Kauric, E. (2001). Integrated care of the older patient. Topics in Clinical Chiropractic, 8(2), 46.

Kolanowski, A. M., Litaker, M., \& Buettner, L. (2005). Efficacy of theory-based activities for behavioral symptoms of dementia. Nursing Research, 54(4), 219228.

Kronman, A. C., Ash, A. S., Freund, K. M., Hanchate, A., \& Emanuel, E. J. (2008). Can primary care visits reduce hospital utilization among Medicare beneficiaries at the end of life? Journal of General Internal Medicine, 23(9), 1330-1335.

Lehman, S., \& Rabins, P. (1999). Clinical geropsychiatry. In W. Reichel, J. Gallo, J. Busby-Whitehead, P. Rabins, S. R. \& J. Murphy (Eds.), Care of the elderly: Clinical aspects of aging (5th ed.). Philadelphia: Lipincott Williams.

Lichtenberg, P., \& McGorgan, A. (1987). Chronic pain in elderly psychiatric patients. Clinical Biofeedback and Health, 10, 3-7.

Lorenz, K. A., Shugarman, L. R., \& Lynn, J. (2006). Health care policy issues in end-oflife care. Journal of Palliative Medicine, 9(3), 731-748.

Luchins, D., Hanrahan, P., \& Murphy, K. (1997). Criteria for enrolling dementia patients in hospice care. Journal of the American Geriatrics Society, 45(9), 1054-1059.

Magaziner, J., German, P., Zimmerman, S. I., Hebel, J. R., Burton, L., Gruber-Baldini, A. L., et al. (2000). The prevalence of dementia in a statewide sample of new nursing home admissions aged 65 and older: Diagnosis by expert panel. Gerontologist, 40(6), 663-672.

Marx (2007). Working with hospice teams to improve pain management in nurisng homes. Journal of the American Ostwopathic Association, 107(6), 22-27.

Marzinski, L. R. (1991). The tragedy of dementia: Clinically assessing pain in the confused nonverbal elderly. Journal of Gerontological Nursing, 17(6), 25-28.

Maslow, K., \& Mezey, M. (2008). Recognition of dementia in hospitalized older adults. American Journal of Nursing, 108(1), 40-50. 
McCaffery, M. (1999). Controlling pain. Assessing pain in a confused or nonverbal patient [corrected] [published erratum appears in NURSING 1999 Oct; 29(10): 14]. Nursing, 29(7), 18-18.

McCance, K. L., \& Huether, S. E. (Eds.). (2006). Pathophysiology: The biologic basis for disease in adults and children (5th ed.). St. Louis, Missouri: Elsevier Mosby.

McCann, J. J., Gilley, D. W., Hebert, L. E., Beckett, L. A., \& Evans, D. A. (1997). Concordance between direct observation and staff rating of behavior in nursing home residents with Alzheimer's disease. Journals of Gerontology Series B: Psychological Sciences \& Social Sciences, 52B(2), 63-72.

Melzack, R., \& Casey, K. (1968). Sensory, motivational, and central control determinants of pain. In D. Kenshalo \& C. C. Thomas (Eds.), The skin senses (pp. 423-443). Springfield, IL: Thomas.

Melzack, R., \& Wall, D. (1988). The challenge of pain. London: Penguin Books.

Mentes, J., Culp, K., Maas, M., \& Rantz, M. (1999). Acute confusion indicators: Risk factors and prevalence using MDS data. Research in Nursing \& Health, 22(2), 95105.

Miller, S. C., Mor, V., \& Teno, J. (2003). Hospice enrollment and pain assessment and management in nursing homes. Journal of Pain \& Symptom Management, 26(3), 791-799.

Miller, S. C., Mor, V., Wu, N., Gozalo, P., \& Lapane, K. (2002). Does receipt of hospice care in nursing homes improve the management of pain at the end of life? Journal of the American Geriatrics Society, 50(3), 507-515.

Mitchell, S. L. (2007). A 93-year-old man with advanced dementia and eating problems. JAMA, 298(21), 2527-2536.

Mitchell, S. L., Kiely, D. K., Hamel, M. B., Park, P. S., Morris, J. N., \& Fries, B. E. (2004). Estimating prognosis for nursing home residents with advanced dementia. JAMA, 291(22), 2734-2740.

Mitchell, S. L., Morris, J. N., Park, P. S., \& Fries, B. E. (2004). Terminal care for persons with advanced dementia in the nursing home and home care settings. Journal of Palliative Medicine, 7(6), 808-816.

Monroe, T. (2010). Dying with dementia and malignant cancer in the nursing home: A retrospecive study. The University of Tennessee Health Science Center, Memphis.

Monroe, T., \& Carter, M. (2009). Evaluating the reliability and validity of the discomfort behavior scale. The University of Tennessee Health Science Center. 
Monroe, T., \& Carter, M. (2010). Hospice care in US nursing homes: Benefits and barriers. European Journal of Palliative Care, 17(3), 144-149.

Morris, J., Brant E., Fries, D., Mehr, C., Phillips, C., Mor, V., et al. (1994). MDS cognitive performance scale. Journal of Gerontology 49(4), m174-m182.

Mulugeta, E., Molina-Holgado, F., Elliott, M. S., Hortobagyi, T., Perry, R., Kalaria, R. N., et al. (2008). Inflammatory mediators in the frontal lobe of patients with mixed and vascular dementia. Dementia \& Geriatric Cognitive Disorders, 25(3), 278-286.

Munn, J. C., Hanson, L. C., Zimmerman, S., Sloane, P. D., \& Mitchell, C. M. (2006). Is hospice associated with improved end-of-life care in nursing homes and assisted living facilities? Journal of the American Geriatrics Society, 54(3), 490-495.

Ogawa, S., \& Lee, T. (1990). Magnetic resonance imaging of blood vessels at high fields: In vivo and in vitro measurments and image simulation. Magnetic Resoncance Medicine, 16, 9-18.

Ogawa, S., Lee, T., Nayak, A., \& Glynn, P. (1990). Oxygenation-sensitive contrast in magnetic resonance image of rodent brain at high magenetic fields. Magnetic Resonance Medicine, 14, 68-78.

Pahor, M., Guralnik, J. M., Wan, J. Y., Ferrucci, L., Penninx, B. W., Lyles, A., et al. (1999). Lower body osteoarticular pain and dose of analgesic medications in older disabled women: The Women's Health and Aging Study. American Journal of Public Health, 89(6), 930-934.

Paquay, L., De Lepeleire, J., Schoenmakers, B., Ylieff, M., Fontaine, O., \& Buntinx, F. (2007). Comparison of the diagnostic accuracy of the Cognitive Performance Scale (Minimum Data Set) and the mini-mental state exam for the detection of cognitive impairment in nursing home residents. International Journal of Geriatric Psychiatry, 22(4), 286-293.

Parham, L. (2002). Contrasts in care work: Hospice care in nursing homes (Doctoral dissertation) Retrieved July 17, 2008, from http://fs.aleph.fcla.edu/F/5BX3Y1FQMCI2V69V2XU9SVSU1QIYF21959T96J4 L8FUB6HX532-31842? func=full-setset\&set number $=002202 \&$ set entry $=000001 \&$ format $=999$

Parker-Oliver, D. (2002). Hospice experience and perceptions in nursing homes. Journal of Palliative Medicine, 5(5), 713-720.

Parker-Oliver, D., \& Bickel, D. (2002). Nursing home experience with hospice. Journal of the American Medical Directors Association, 3(2), 46-50. 
Parker-Oliver, D., Porock, D., Zweig, S., Rantz, M., \& Petroski, G. F. (2003). Hospice and nonhospice nursing home residents. Journal of Palliative Medicine, 6(1), 6975.

Pasero, C., \& McCaffery, M. (2001). Pain control. The undertreatment of pain: Are providers accountable for it? American Journal of Nursing, 101(11), 62-63.

Pasero, C., \& McCaffery, M. (2005). Pain control. No self-report means no pain-intensity rating: Assessing pain in patients who cannot provide a report. American Journal of Nursing, 105(10), 50.

Petrisek, A. C., \& Mor, V. (1999). Hospice in nursing homes: A facility-level analysis of the distribution of hospice beneficiaries. Gerontologist, 39(3), 279-290.

Plassman, B. L., Langa, K. M., Fisher, G. G., Heeringa, S. G., Weir, D. R., Ofstedal, M. B., et al. (2008). Prevalence of cognitive impairment without dementia in the United States. Annals of Internal Medicine, 148(6), 427-434.

Pleschberger, S. (2007). Dignity and the challenge of dying in nursing homes: The residents view. Age and Aging, 36, 197-202.

Price, D. D. (2000). Psychological and neural mechanisms of the affective dimension of pain. Science, 288(5472), 1769-1772.

Rainero, I., Vighetti, S., Bergamasco, B., Pinessi, L., \& Benedetti, F. (2000). Autonomic responses and pain perception in Alzheimer's disease. European Journal of Pain: EJP, 4(3), 267-274.

Reisberg, B. (1984). Alzheimer's disease: Stages of cognitive decline. American Journal of Nursing, 84(2), 225.

Reisberg, G. (1988). Functional assessment staging (FAST). Psychopharmacological Bulleting, 24, 653-659.

Reynolds, K., Henderson, M., Schulman, A., \& Hanson, L. C. (2002). Needs of the dying in nursing homes. Journal of Palliative Medicine, 5(6), 895-901.

Rice, K. N., Coleman, E. A., Fish, R., Levy, C., \& Kutner, J. S. (2004). Factors influencing models of end-of-life care in nursing homes: Results of a survey of nursing home administrators. Journal of Palliative Medicine, 7(5), 668-675.

Rub, U., Del Tredici K, Del Turco, D., \& Braak, H. (2002). The intralaminar nuclei assigned to the medial pain system and other components of this system are early and progressively affected by the Alzheimer's disease-related cytoskeletal pathology. Journal of Chemical Neuroanatomy, 23, 279-290.

Ryan, J., Stone, R. I., \& Raynor, C. R. (2004). Using large data sets in long-term care to measure and improve quality. Nursing Outlook, 52(1), 38-44. 
Sachs, G. A., Shega, J. W., \& Cox-Hayley, D. (2004). Brariers to excellent end-of-life care for patients with dementia. Journal of General Internal Medicine, 19(10), 1057-1063.

Scherder, E., \& Bouma, A. (1997). Is decreased use of analgesics in Alzheimer disease due to a change in the affective component of pain? Alzheimer Disease \& Associated Disorders, 11(3), 171-174.

Scherder, E., \& Bouma, A. (2000). Visual analogue scales for pain assessment in Alzheimer's disease. Gerontology, 46, 47-53.

Scherder, E., Bouma, A., Borkent, M., \& Rahman, O. (1999). Alzheimer patients report less pain intensity and pain affect than non-demented elderly. Psychiatry, 62(3), 265-272.

Scherder, E., Knol, D., van Someren, E., Deijen, J., Binnekade, R., Tilders, F., et al. (2003). Effects of low-frequency cranial electrostimulation on the rest-activity rhythm and salivary cortisol in Alzheimer's disease. Neurorehabilitation \& Neural Repair, 17(2), 101-108.

Scherder, E., Oosterman, J., Swaab, D., Herr, K. A., Ooms, M., Ribbe, M., et al. (2005). Recent developments in pain in dementia. BMJ: British Medical Journal, 330(7489), 461-464.

Scherder, E. J. A., Sergeant, J. A., \& Swaab, D. F. (2003). Pain processing in dementia and its relation to neuropathology. Lancet Neurology, 2(11), 677-686.

Stevenson, K. M., Brown, R. L., Dahl, J. L., Ward, S. E., \& Brown, M. S. (2006). The discomfort behavior scale: A measure of discomfort in the cognitively impaired based on the minimum data set 2.0. Research in Nursing \& Health, 29(6), 576587.

Stolee, P., Hillier, L. M., Esbaugh, J., Bol, N., McKellar, L., \& Gauthier, N. (2005). Progress in geriatrics: Instruments for the assessment of pain in older persons with cognitive impairment. Journal of the American Geriatrics Society, 53(2), 319326.

Tarzian, A. J., \& Hoffmann, D. E. (2006). A statewide survey identifying perceived barriers to hospice use in nursing homes. Journal of Hospice \& Palliative Nursing, 8(6), 328-337.

Taylor, D. H., Jr., Ostermann, J., Van Houtven, C. H., Tulsky, J. A., \& Steinhauser, K. (2007). What length of hospice use maximizes reduction in medical expenditures near death in the US Medicare program? Social Science \& Medicine, 65(7), 14661478.

Teng, E., \& Chui, H. (1987). The modified mini-mental state (3MS) examination. Journal of Clinical Psychiatry, 48(8), 314-318. 
Teno, J. M., Clarridge, B. R., Casey, V., Welch, L. C., Wetle, T., Shield, R., et al. (2004). Family perspectives on end-of-life care at the last place of care. JAMA, 291(1), 88-93.

Thompson, P., Hayashi, K., de Zubicaray, G., \& Jones, A. (2003). Dynamics of grey matter loss in Alzheimer's disease. Journal of Neruoscience, 23, 994-1005.

Tombaugh, T., \& McIntyre, N. (1992). The mini-mental state examination: A comprehensive review. Journal of the American Geriatrics Society, 40, 922-935.

Treede, R. D., Kenshalo, D. R., Gracely, R. H., \& Jones, A. K. (1999). The cortical representation of pain. Pain, 79(2-3), 105-111.

Tsai, P. F., Beck, C., Richards, K. C., Phillips, L., Roberson, P. K., \& Evans, J. (2008). The pain behaviors for osteoarthritis instrument for cognitively impaired elders (PBOICIE). Research in Gerontological Nursing, 1(2), 116-122.

U. S. Department of Health and Human Services (2000a). Minimum Data Set (MDS) Version 2.0. Retrieved July 12, 2008, from http://www.cms.hhs.gov/NursingHomeQualityInits/downloads/MDS20MDSAllF orms.pdf

U. S. Department of Health and Human Services (2000b). Outcomes and utilization for hospice and non-hosptice nursing facility decedents. Retrieved December 20, 2008, from http://aspe.hhs.gov/daltcp/Reports/oututil.htm

U. S. Department of Health and Human Services (2000c). Synthesis and analysis of Medicare's hospice benefit: Executive summary and recommendations. Retrieved December 20, 2008, from http://aspe.hhs.gov/daltcp/reports/samhbes.htm

Weiner, D., Peterson, B., \& Keefe, F. (1998). Evaluating persistent pain in long term care residents: What role for pain maps. Pain, 76, 249-257.

Weiner, D., Peterson, B., \& Keefe, F. (1999). Chronic pain-associated behaviors in the nursing home: Resident versus caregiver perceptions. Pain, 80, 577-588.

Weissman, D., \& Matson, S. (1999). Pain assesment and management in the long-term care setting. Theoretical Medicine, 20, 31-43.

Woo, J., Ho, S. C., Lau, J., \& Leung, P. C. (1994). Musculoskeletal complaints and associated consequences in elderly Chinese aged 70 years and over. Journal of Rheumatology, 21(10), 1927-1931.

World Health Organization (2006). Alzheimer's disease: The brain killer. Retrieved November 3, 2008, from http://www.searo.who.int/en/Section1174/Section1199/Section1567/Section1823 8057.htm 
Wu, N., Miller, S. C., Lapane, K., \& Gozalo, P. (2003). The problem of assessment bias when measuring the hospice effect on nursing home residents' pain. Journal of Pain \& Symptom Management, 26(5), 998-1009. 


\section{APPENDIX A. LETTER OF APPROVAL - INSTITUTIONAL REVIEW BOARD}

\begin{tabular}{lr}
\hline THE UNIVERSITY OF TENNESSEE \\
Health Science Center
\end{tabular}

March 16, 2009

Todd Bryant Monroe

College of Graduate Health Sciences

Department of Nursing

201 Molecular Sciences Building

Re: 09-00314-XM: Pain Management in Nursing Home Residents with Cancer and Dementia with and without Hospice Services

Dear Mr. Monroe,

The Administrative Section of the UTHSC Institutional Review Board (IRB) reviewed your application for the above referenced project.

The Administrative Section of the IRB determined your application to be consistent with the guidelines for exempt review under 45 CFR 46.101(b)(4). Informed consent is waived in accord with 45 CFR46.116 (d).

Therefore your application has been determined to comply with proper consideration for the rights and welfare of human subjects and the regulatory require ments for the protection of human subjects. This letter constitutes full approval of your application and data collection tool for the above referenced study.

This study may not be initiated until you receive approval from the institution(s) where the research is being conducted.

In the event that volunteers are to be recruited using solicitation materials, such as brochures, posters, webbased advertisements, etc., these materials must receive prior approval of the IRB.

Any alterations (revisions) in the protocol must be promptly submitted to and approved by the UTHSC Institutional Review Board prior to implementation of these revisions. You have individual responsibility for reporting to the Board in the event of unanticipated or serious adverse events and subject deaths.

Sincerely,

Signature applied by Terrence F Ackerman on 03/16/2009 12:18:58 PM CST



Signature applied by Donna L Stallings on 03/16/2009 12:19:49 PM CST<smiles>CCCCOc1cccc(OCC)c1OCC(C)C</smiles>

Terrence F. Ackerman, Ph.D.

Chairman

UTHSC IRB

Donna Stallings, CIM

IRB Administrator 


\section{APPENDIX B. LETTER OF APPROVAL REVISION - INSTITUTIONAL REVIEW BOARD}

\begin{tabular}{lr}
\hline THE UNIVERSITY OF TENNESSEE \\
Health Science Center
\end{tabular}

May 21,2009

Todd Bryant Monroe

College of Graduate Health Sciences

201 Molecular Sciences Building

Re: 09-00314-XM: Pain Management in Nursing Home Residents with Cancer and Dementia with and without Hospice Services

Dear Mr. Monroe,

The Administrative Section of the UTHSC Institutional Review Board (IRB) reviewed your application for revision of your previously approved project, referenced above.

The Administrative Section of the IRB determined your application to be consistent with the guidelines for exempt status under 45CFR46.101(b)(2). Therefore, the attached revisions to your project were approved in this regard as complying with proper consideration of the rights and welfare of human subjects, the risk involved, and the potential benefits of the study.

The revisions to this study may not be instituted until you recive approval from the institution(s) where the research is being conducted.

In the event that volunteers, either subjects or patients, are to be recruited by means other than usual and standard patient care practices, the Board must approve of any such solicitation materials (i.e., advertising copies or posters, etc.)

Any alterations (revisions) in the research project must be submitted to and approved by the UTHSC Institutional Review Board prior to implementation to these revisions.

Sincerely,

Signature applied by Donna L Stallings on 05/21/2009 12:20:47 PM CDT

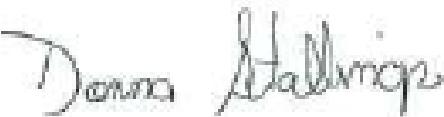

Signature applied by Terrence F Ackerman on 05/21/2009 12:21:18 PM CDT



Donna Stallings, CIM

IRB Analyst

UTHSC IRB
Terrence F. Ackerman, Ph. D.

Chairman

UTHSC IRB

Attachment: Revisions 
Todd Bryant Monroe

Re: 09-00314-XM

May 21, 2009

Page -2-

1. Study Application Version 1.1 is revised to reflect (a) additional study sites: Court Manor Nursing Home, 1414 Court Avenue, Memphis, TN; Bright Glade Nursing Home, 5070 Sanderlin Avenue, Memphis, TN; Wesley Highland Manor, 3549 Norris Wood Avenue, Memphis, TN; Covington Care Nursing Home, 765 Bert Johnson Avenue, Covington, TN and Dyersburg Manor Nursing Home Center, 1900 Parr Avenue, Dyersburg, TN. 


\section{APPENDIX C. MEDICAL CHART REVIEW FORM}

Subject ID

LTCF

Date

Recorder

Pain Assessment and Management Form (PAM)

Dementia Diagnoses (from the medical record) ICD9 codes

Diagnosis of malignant cancer confirmed in the medical record Cause of death related to cancer confirmed in the medical record Hospice services $\square$ yes $\square$ no

\begin{tabular}{|l|l|l|l|l|l|}
\hline OPIOID ANALGESICS & Dose & Route & $\begin{array}{l}\text { Doses over } \\
14 \text { days }\end{array}$ & $\begin{array}{l}\text { Scheduled } \\
\text { Doses }\end{array}$ & $\begin{array}{l}\text { PRN } \\
\text { Doses }\end{array}$ \\
\hline Morphine Sulfate & & & & & \\
\hline $\begin{array}{l}\text { Controlled Released Morphine } \\
\text { (MS Contin, Roxanol SR, } \\
\text { Avinza) }\end{array}$ & & & & & \\
\hline Hydromorphome (Dilaudid) & & & & & \\
\hline Oxymorphone (Numorphan) & & & & & \\
\hline Levorphanol (Levo-Dromoran) & & & & & \\
\hline Codeine & & & & & \\
\hline $\begin{array}{l}\text { Oxycodone (Roxicet, Percocet, } \\
\text { Percodan, Tylox) }\end{array}$ & & & & & \\
\hline Hydrocodone (Vicodin, Lortab) & & & & & \\
\hline $\begin{array}{l}\text { Propoxyphene (Darvocet, } \\
\text { Darvon, Wygesic) }\end{array}$ & & & & & \\
\hline Meperidine (Demerol) & & & & & \\
\hline Fentanyl (Duragesic) & & & & & \\
\hline Pentazine (Talwin) & & & & & \\
\hline Nalbuphine (Nubain) & & & & & \\
\hline Buprenorphine (Buprenex) & & & & & \\
\hline Other & & & & & \\
\hline Acetaminophen & & & & \\
\hline Ibuprofen & & & & \\
\hline
\end{tabular}




\begin{tabular}{|l|l|l|l|l|l|}
\hline POTENTIATORS & Dose & Route & $\begin{array}{l}\text { Total dose amount } \\
\text { over last 14 days } \\
\text { of life }\end{array}$ & $\begin{array}{l}\text { Scheduled } \\
\text { doses }\end{array}$ & PRN doses \\
\hline & & & & & \\
\hline & & & & & \\
\hline & & & & & \\
\hline & & & & & \\
\hline & & & & & \\
\hline & & & & & \\
\hline & & & & & \\
\hline & & & & & \\
\hline & & & & & \\
\hline & & & & & \\
\hline & & & & & \\
\hline & & & & & \\
\hline
\end{tabular}




\section{VITA}

Todd Monroe was born in Little Rock, Arkansas on August 28, 1970. He attended Brinkley High School in Brinkley, Arkansas and later attended The University of Arkansas at Little Rock where he earned a BA in 1992. In 1998 he received a BSN cum laude from The University of Southern Mississippi in Hattiesburg, Mississippi. He worked as a staff nurse at Methodist University Hospital in Memphis, Tennessee until 2001 when he entered the master's program in nursing at The University of Alabama and graduate in 2002. He then worked as a case manager in home health for the Arkansas Department of Health. In 2007, he received a MS in Educational Leadership from The University of Memphis. In 2007, Todd was accepted into the Nursing doctoral program at The University of Tennessee Health Science Center in Memphis, Tennessee. His dissertation research focused on pain in older adults with cancer and dementia with and without hospice services. In 2008 he returned to Methodist University Hospital where he continues to work as a staff nurse and will graduate with a degree of Doctor of Philosophy with a major in Nursing in May 2010. Todd has accepted a post-doctoral position at Vanderbilt University School of Nursing in Nashville, Tennessee. 